\title{
Development and Design of Binder Systems for Titanium Metal Injection Molding: An Overview
}

\author{
GUIAN WEN, PENG CAO, BRIAN GABBITAS, DELIANG ZHANG, \\ and NEIL EDMONDS
}

\begin{abstract}
Titanium metal injection molding (Ti-MIM) has been practiced since the late 1980s. Logically, the Ti-MIM practice follows the similar processes developed for the antecedent materials such as stainless steel and ceramics. Although Ti-MIM is a favorite research topic today, the issue of convincing the designers to use Ti injection-molded parts still exists. This is mainly because of the concern about contamination which seems unavoidable during the Ti-MIM process. Much information about the binder formulation, powder requirements, debinding, and sintering is available in the literature. There are several powder vendors and feedstock suppliers. However, most of the binders in the feedstock are proprietarily protected. The disclosed information on the binders used for formulating powder feedstock is very limited, which in turn discourages their adoption by engineering designers. This overview intends to discuss some of major binder systems for Ti-MIM available in the literature. It serves to provide a guideline for the Ti-MIM practitioners to choose a suitable powder feedstock.
\end{abstract}

DOI: $10.1007 / \mathrm{s} 11661-012-1485-\mathrm{x}$

(C) The Minerals, Metals \& Materials Society and ASM International 2012

\section{INTRODUCTION}

TITANIUM and its alloys are considered as materials of great interest because of their unique combination of low density, high specific strength, biocompatibility, and excellent corrosion resistance. ${ }^{[1,2]}$ However, the high production cost of titanium components limits their applications. ${ }^{[3,4]}$ Powder metallurgy, especially near-netshaping technologies, offers a promise to reduce the manufacturing cost of titanium products. In the powder metallurgy regime, powder or metal injection molding (PIM/MIM) is recognized as a premier forming method ideal for mass production of parts with medium-to-small size and complex shapes. ${ }^{[5]}$ Not until the late 1980 s was the MIM process trialed in titanium powder. ${ }^{[6]}$ Two decades of development have seen significant progress in titanium metal injection molding (Ti-MIM) and some products have been commercially available for many years, for example, a Hitachi Ti alloy watch case. ${ }^{[7]}$ Some other products have been showcased for dental implants, medical devices, and golf clubs. ${ }^{[8]}$ Figure 1 presents some examples of Ti-MIM products. Nevertheless, the Ti-MIM technology has not seen significant breakthroughs, especially in advanced engineering components for aerospace applications. It has been claimed that

GUIAN WEN, Post Doctoral Fellow, and PENG CAO, Senior Lecturer, are with the Department of Chemical and Materials Engineering, The University of Auckland, Private Bag 92019, Auckland 1142, New Zealand. Contact e-mail: p.cao@auckland.ac.nz BRIAN GABBITAS, Associate Professor, and DELIANG ZHANG, Professor, are with the School of Engineering, The University of Waikato, Hamilton, New Zealand. NEIL EDMONDS, Senior Lecturer, is with the School of Chemical Science, The University of Auckland, Private Bag 92019, Auckland 1142, New Zealand.

Manuscript submitted January 30, 2012. technically the Ti-MIM process is ready for industry to take up, particularly for applications where the use of titanium is fully justified by its unique properties. ${ }^{[8]}$ These include, for example, dental and biomedical implants, aerospace components, medical and surgical tools, and chemical devices. ${ }^{[8]}$ Although Ti-MIM is a favorite research topic today, ${ }^{[8]}$ the issue of convincing the designers to use titanium parts made using Ti-MIM still has not been satisfactorily addressed. Much information on how to make titanium parts using Ti-MIM is available, and there are several powder vendors and feedstock suppliers. However, most of the binders in the feedstock are proprietarily protected. Contaminants, either in the original titanium powder, from the sintering atmosphere, or most likely from the binder, are usually a big concern for the component designers because these impurities deleteriously affect the mechanical properties of the final products. ${ }^{[9,10]}$ In this sense, a comprehensive understanding of the binder system and the debinding processes helps us to provide a guideline for choosing a suitable powder feedstock and to validate the MIM approach. Research, development, and market status of MIM processes has been regularly reviewed, ${ }^{\left[{ }^{8,11-13]}\right.}$ and they do not form the scope of this article. Rather, it intends to give an overview of the binders developed for Ti-MIM with a focus on discussing some of the major binder systems for Ti-MIM.

\section{BASICS OF BINDERS FOR MIM}

Figure 2 illustrates schematically a generic MIM process that includes four major processing steps: feedstock formulation, injection molding, debinding, and sintering. ${ }^{[14]}$ The MIM process starts with the preparation of a homogeneous powder feedstock by 

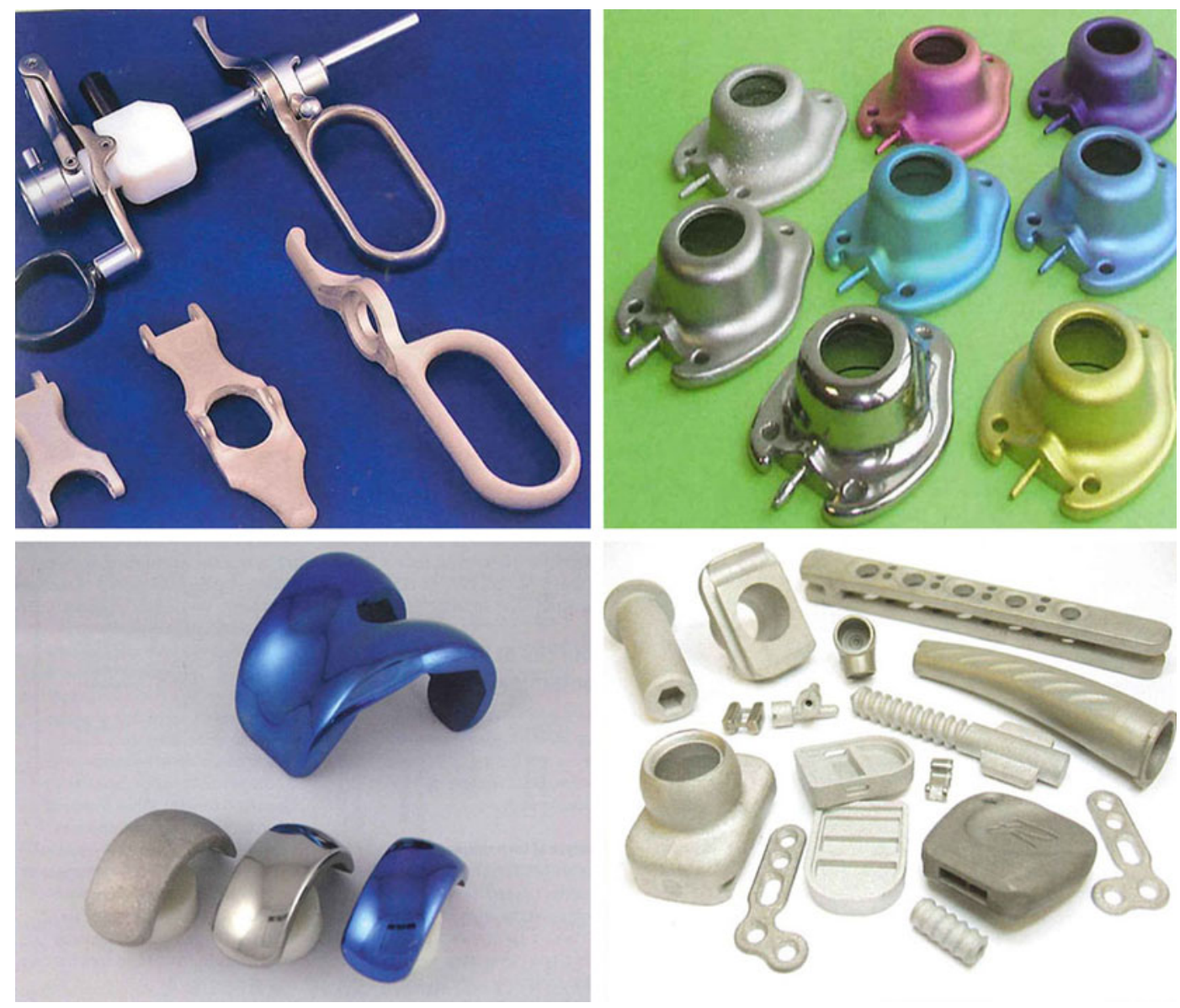

Fig. 1-Some examples of Ti components made by MIM technique. Courtesy of PIM International.

mixing metal powders with a suitable binder system. The homogeneity of a powder feedstock is crucial for MIM processing. Any inhomogeneity, including bubbles, left during the mixing step will be carried over to the subsequent processing steps. An inhomogeneous feedstock usually leads to a poor flow behavior during molding and difficulty of densification and dimensional stability in the final products. In order to achieve a homogeneous feedstock, the significance of binder selection cannot be overemphasized. The binder in the powder feedstock is a temporary vehicle for shaping the feedstock into the required geometry and holding the particles in that shape until the start of sintering. Although the binder should not dictate the final composition of the molded materials, it has a major influence on the MIM processing. Ideally, the binder should meet the following criteria: ${ }^{[15]}$

(a) Having a low melting temperature and quickly solidify.

(b) Having sufficient strength at room temperature $(\geq 4 \mathrm{MPa})$, a low viscosity ( $\leq 10 \mathrm{~Pa} \mathrm{~s}),{ }^{[15]}$ and good fluidity at the molding temperature. Its viscosity should not change during the injection molding process.

(c) Being chemically passive and having the ability to wet the particle with a low contact angle $(<5 \mathrm{deg})$ and ideally adhere to the particle surface.

(d) Being easily removable after shaping and ideally not leaving any residue that potentially causes contamination. The decomposed byproducts should be noncorrosive and nontoxic.

(e) Being commercially available and practically affordable.

It is very difficult to find or develop a single material to meet all of the above criteria. In general, the binder formulations consist of at least two components: a major component (such as wax), and a secondary component that is usually a high molecular-weight polymer. The major component is used to wet the metallic powder particles and provide necessary flowability, while the polymeric component, also called a backbone component, ensures a sufficient green strength after injection molding and/or after the major component is removed. In most cases, the binder system also contains a third component, such as a surfactant, which improves compatibility between the metallic powders and the polymer. All of the binder components should be compatible with each other.

Some of the above mentioned requirements are even more stringent for Ti-MIM. ${ }^{[16,17]}$ This is because titanium is a well-known universal solvent for many impurities such as hydrogen, oxygen, carbon, and nitrogen. ${ }^{[18-20]}$ The contamination issue, and its effect on mechanical properties is therefore most challenging for Ti-MIM and is always the greatest hurdle in 


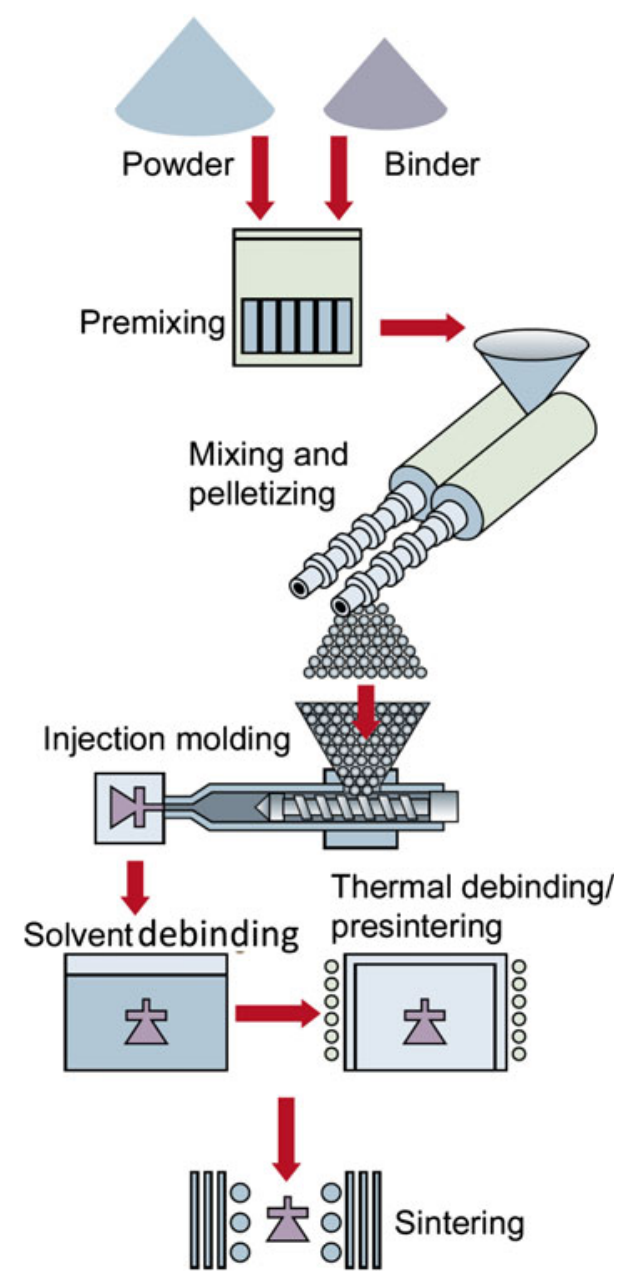

Fig. 2-Schematic of generic metal injection molding processes: feedstock formulation, injection molding, debinding, and sintering: redrawn from Ref. [14] with permission.

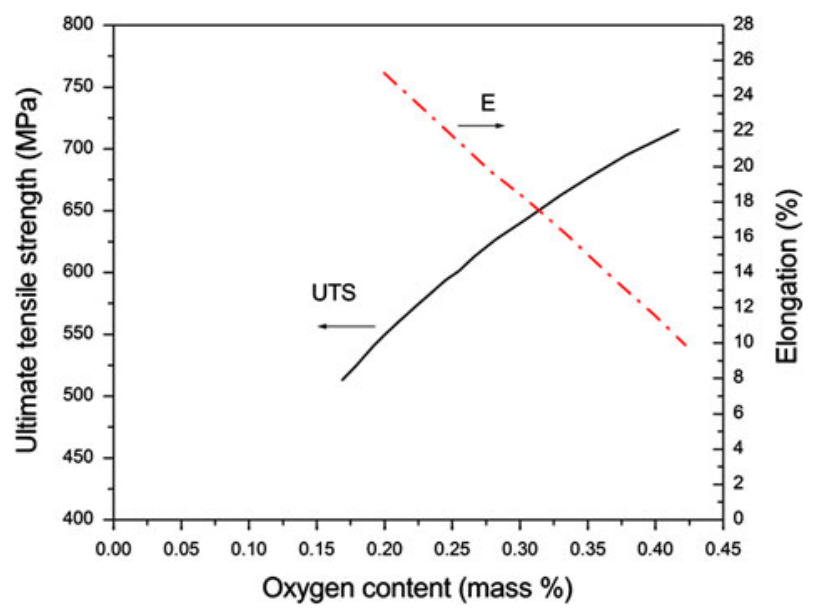

Fig. 3- General effect of oxygen content on mechanical properties of titanium. The diagram shows a significant increase in tensile strength while a remarkable reduction in ductility with increasing oxygen content, redrawn from Ref. [14] with permission.

convincing the product designers to use this technology. It is known that when the processing temperature approaches $673 \mathrm{~K}\left(400{ }^{\circ} \mathrm{C}\right)$, bulk titanium starts to react with oxygen, nitrogen, and hydrogen, forming oxides, nitrides, and hydrides, respectively. ${ }^{[10,11]}$ For titanium powders, this oxidation temperature could be much lower. Among these impurities, nitrogen has the most significant effect, followed by oxygen and carbon. However, it is noted that controlling oxygen content is usually more difficult than for other impurities. ${ }^{[21]}$ The effect of these impurities is often reflected by an oxygen equivalent formula such as $\mathrm{O}_{\mathrm{eq}}=\mathrm{O}+2 \mathrm{~N}+0.75$ C. ${ }^{[22,23]}$ In general, these interstitials increase the yield strength of titanium and titanium alloys, but significantly reduce their ductility and fracture toughness. For instance, Figure 3 shows the influence of oxygen content on the mechanical performance of Ti components, and an empirical formula was given to relate yield strength $\sigma_{\mathrm{y}}$ of the sintered titanium to the fractional density $\rho$ and oxygen equivalent $\mathrm{O}_{\mathrm{eq}}$ as $\sigma_{\mathrm{y}}=(420+970$. $\left.\mathrm{O}_{\mathrm{eq}}\right) \cdot \rho \cdot{ }^{[14]}$ Ebel et al. also found that both yield strength and ultimate tensile strength (UTS) of Ti-6Al-4V linearly increase with oxygen equivalent. ${ }^{[24]}$

In Ti-MIM, removing the backbone additive represents the most challenging factor influencing contamination control. This is because the backbone polymer, which is added to confer the rigidity to the molded parts, usually has a high molecular weight and is not easily decomposed. Also the presence of large amounts of organic materials - the major component, which are a pre-requisite for efficient and reproducible molding operations, can lead to undesirable levels of carbonbased impurities in the final sintered bodies. An unsuitable binder composition selection and/or poor process control during the debinding and sintering steps can result in incomplete removal of the binder material. Currently, there are a number of ASTM standards that specify the requirements of different grades of titanium products such as F67, ${ }^{[25]} \mathrm{F} 136,{ }^{[26]} \mathrm{B} 348,{ }^{[27]}$ and B817. ${ }^{[28]}$ ASTM-F2885 ${ }^{[29]}$ covers Ti-6Al-4V made by MIM for surgical implant applications, while another standard ASTM-WK35394 covering unalloyed Ti-MIM has been placed under development. The Ti-MIM products must at least meet the requirements specified in one of these ASTM standards, for example, F2885 (Ti-6Al-4V by MIM) or B817 (Powder Metallurgy titanium).

The thermal decomposition behaviors of polymers, which serve as the backbone component in binder system, are complicated, and hence a brief introduction of it is given here. The commonly used polymers (thermoplastics) are composed of carbon, hydrogen, and optionally oxygen, nitrogen, and other elements. Ideally, the polymeric binder components should have a minimum of these elements with as simple a chain structure as possible. As indicated in the formula for oxygen equivalent, nitrogen has the strongest influence, and therefore, in the design of a binder, only minimum amounts of nitrogen-containing polymers should be used or preferably avoided. The presence of nitrogen usually enhances thermal stability of a polymer, because of factors such as hydrogen bonding. Also, the presence of aromatic groups, such as benzene and/or fused benzene rings in macromolecules, dramatically increases thermal decomposition temperatures, and therefore, polymers containing aromatic groups are not a good 
choice for Ti-MIM. Second, the backbone polymer should decompose completely at as low a temperature as possible. Unfortunately, most engineering plastics have a wide range of decomposition temperatures up to $873 \mathrm{~K}\left(600^{\circ} \mathrm{C}\right) \cdot{ }^{[30]}$ The decomposition temperature of polymers is influenced by factors such as polymer structure, molecular weight, and crystallinity. For example, the performances of polyethylene including thermal decomposition behavior significantly depend on its polymerization method. In this regard, information about the molecular weight of a polymer is simply not sufficient for binder design or selection. Other information such as chemical structure, molecular weight distribution, and crystallinity is also important, but unfortunately this is often unavailable or purposely proprietary protected. Also, chain branching, unpolymerized double bonds, and the positions of the oxygen atoms in the polymer chain can affect the decomposition temperatures. ${ }^{[30]}$ For instance, because oxygen atoms are in the main chain, polyoxymethylene (POM) has a low decomposition temperature of $453 \mathrm{~K}\left(180{ }^{\circ} \mathrm{C}\right)$, compared with other polymers. Another example is polypropylene (PP), which is less stable than polyethylene $(\mathrm{PE})$, because of its chain branching. Third, the mechanism of thermal decomposition plays an important role in binder removal in the absence of oxygen (pyrolysis). Upon thermal decomposition, aliphatic polyolefins, such as PE and PP, create little amounts of monomers but a large number of different small molecules, mostly hydrocarbons. By contrast, the pyrolysis of polymethyl methacrylate (PMMA) can produce more than 90 pct gaseous monomers under vacuum or inert atmospheres. ${ }^{[30-32]}$ To control and minimize contamination from the binder materials and the debinding process, thermal decomposition behavior needs to be quantified. Table I summarizes the thermal decomposition behaviors of polymers that are commonly used in formulating powder feedstock.

However, it must be pointed out that thermal decomposition is not the only consideration. The binder must also provide other functionalities such as proper fluidity so that injection molding can be accomplished, and sufficient green strength to retain a rigid geometry of the molded parts for handling. Therefore, different considerations must be given to different components in binder design. In addition to the thermal decomposition behavior, processing temperature, viscosity (melt flow index), strength, and compatibility (interaction parameters with other components) must be also taken into account. Liang et $a l^{[33]}$ claimed that the solubility between binder constituents should be taken into consideration when designing a binder system. If the binder components are incompatible, then additives are required to make them compatible with each other. ${ }^{[33]}$

\section{BINDER DEVELOPMENT}

Binders have been used for powder injection molding (PIM) of ceramics and metallic materials for many years. ${ }^{[34]}$ The production of ceramic spark plugs and refractory bodies was first reported in the 1920s, and the first patent was granted in July $1938 .{ }^{[35]}$ In the late 1950s, small-volume PIM ceramic parts including carbides were produced using epoxy, wax, or cellulose binders. ${ }^{[36]}$ The 1980s saw major technical progress being made in the PIM industry, and PIM techniques were commercialized by a number of companies during this period. The number of patents surged in the early 1990 s and stabilized afterward. Figure 4 shows the number of the PIM patents related to binders from 1970 to the present, by searching within the patent worldwide database Espacenet (European Patent Office, http:// worldwide.espacenet.com) and using powder (metal + ceramic) injection moulding (molding) binder as the keywords.

Although PIM has a long history, the first practice of this process on titanium and its alloys did not begin until $1988 .{ }^{[6]}$ Early attempts at developing a viable Ti injection molding process was plagued by the limited availability of suitable powders (in terms of powder size, impurities, and cost), inadequate protection of titanium during elevated temperature processing, and less-thanoptimum binders for reactive materials such as titanium.

Logically, the development of a binder for Ti-MIM draws on the knowledge about the binders developed for other common materials, e.g., stainless steel. The early choices for Ti-MIM were to use the existing binder systems. Afterward, a wide range of binders were tailored for Ti-MIM, which can be classified into four groups according to the techniques involved in the debinding process. We shall discuss these four major groups of binders in the next four subsections: waxbased, POM)based, aromatics-based, and water-soluble binder systems, respectively.

\section{WAX-BASED BINDER SYSTEM}

Attempts at Ti-MIM in the early 1980s utilized thermoplastic or thermoset-based polymers, which are typically used in MIM for other materials such as steel, tungsten, and ceramics. The binder removal is achieved via thermal pyrolysis. ${ }^{[36]}$ For example, in the first published study by Kaneko et al., ${ }^{[6]}$ wax-PBMA [poly(butyl methacrylate)]-EVA -DBP (dibutyl phthalate) was used as the binder and mixed with Ti powders at $413 \mathrm{~K}\left(140{ }^{\circ} \mathrm{C}\right)$. The reported compositions were 56 vol. pet Ti powder, 17 vol. pet PBMA, 21 vol. pct EVA, and 6 vol. pct DBP. After injection molding, the green parts were debound by gradually increasing the temperature to $573 \mathrm{~K}\left(300{ }^{\circ} \mathrm{C}\right)$ in air. The specimens were then sintered at $1573 \mathrm{~K}\left(1300{ }^{\circ} \mathrm{C}\right)$ for 2 hours under a vacuum of $1.3 \mathrm{~Pa}$. A relative density of $94 \mathrm{pct}$ and a compressive strength of $1000 \mathrm{MPa}$ were achieved. However, these sintered specimens exhibited brittle fracture with no ductility (see Figure 5). Follow-up study, carried out in 1990, on Ti-6Al-4V powders showed similar results. ${ }^{[36]}$ The high tensile strength, but little or even no ductility in the sintered parts stem from high amounts of impurities. However, it is not clear from these early reports whether the contamina- 
Table I. Thermal Decomposition Behavior of the Commonly Used Polymers ${ }^{[31]}$

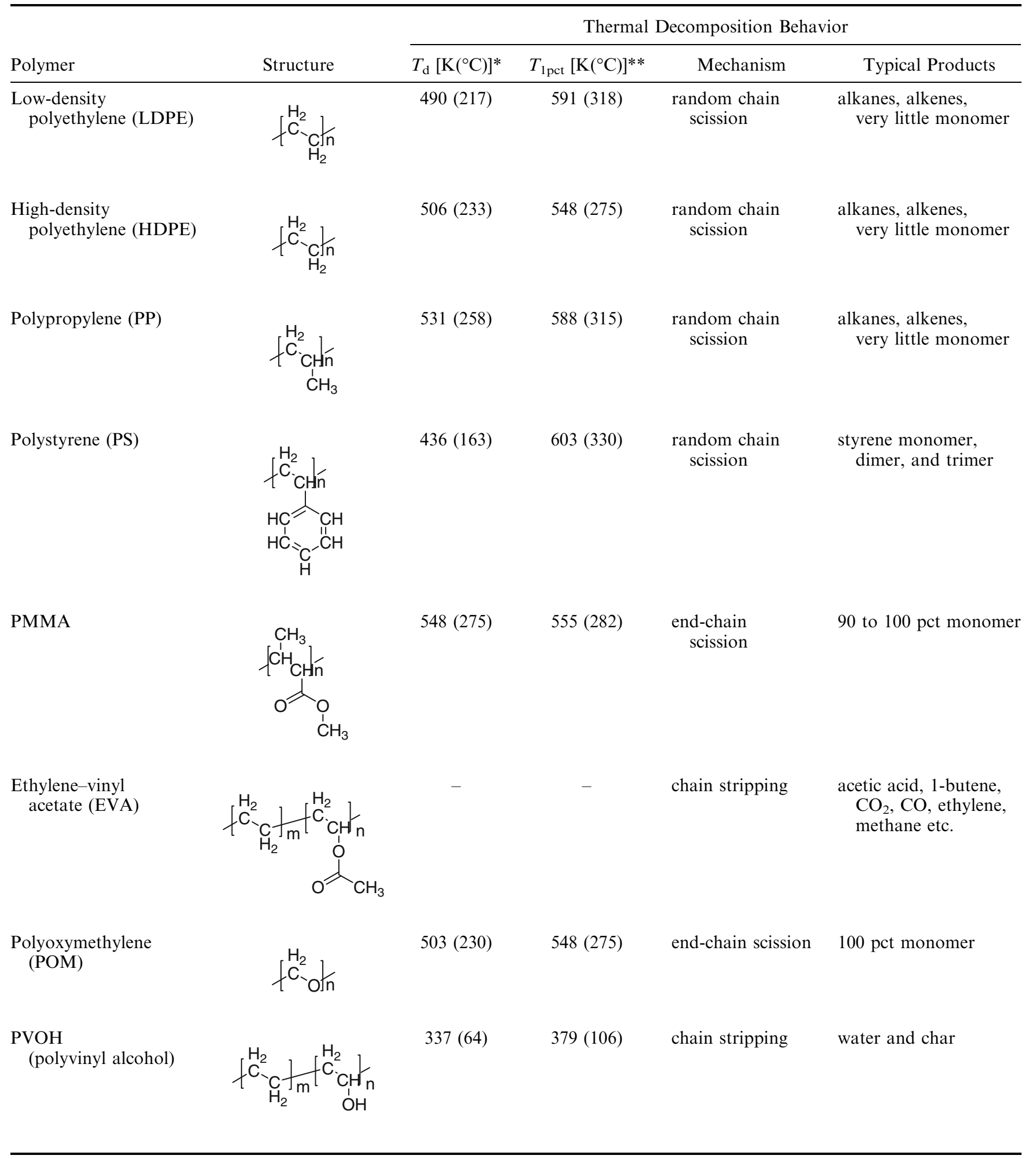

*Indicates the starting decomposition temperature, derived from thermal gravity analysis (TGA) curve $\left(\mathrm{N}_{2}\right.$ atmosphere); **indicates a temperature at which 1 pet thermal decomposition is achieved.

tion was caused by the sintering atmosphere or by incomplete debinding. Nevertheless, it is believed that even if a high-vacuum sintering furnace is used, an incomplete debinding would result in contamination, particularly if the pyrolysis can only be completed at a high temperature, which exceeds the oxidation temperature of titanium. To circumvent incomplete pyrolysis, new binders have been developed, which are soluble in 


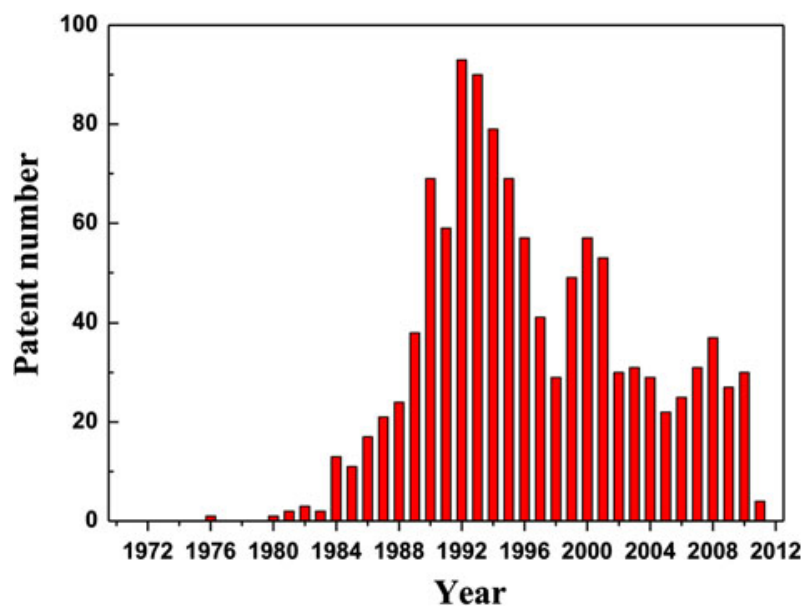

Fig. 4-The number of PIM-related patents granted since 1970, showing extensive research activities and significant progress made in the 1990s (Source: European Patent Office).

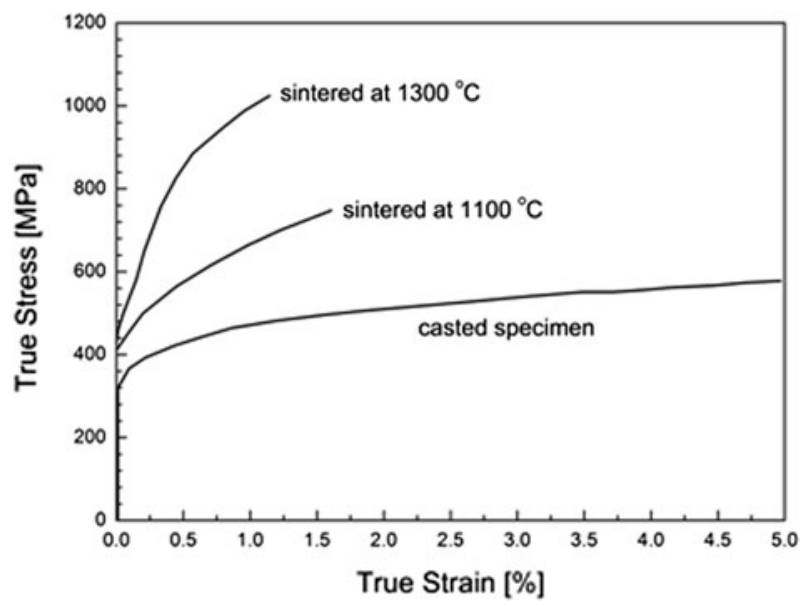

Fig. 5-Early Ti-MIM study by Kaneko et al. ${ }^{[6]}$ in Japan, showing the compression test results. The as-sintered $\mathrm{Ti}$ samples revealed significant higher compression strength than castings. The compression strains ranged from only 1 to 2 pct. The elevated strength but reduced ductility were attributed to the high impurity levels in the samples. organic solvents or contain a catalyst that facilitates in situ decomposition. ${ }^{[37]}$

It appears that removal of the wax-based binder focused on simple one-step thermal pyrolysis. For example, Kato ${ }^{[37]}$ investigated the debinding and sintering of titanium injection-molded parts in a furnace that was first evacuated and then backfilled with flowing argon gas. The attendant poor performance of titanium parts were attributed to severe contamination from oxygen and carbon residues, which was believed to originate from an incomplete burnout. Significant progress was realized by a two-step process, viz. solvent extraction followed by thermolysis. This two-step debinding process significantly reduces the contamination of carbon and oxygen after sintering. ${ }^{[36]}$

The search for wax-based binders for Ti-MIM has never stopped. Guo et al. demonstrated the validity of a modified wax-based binder system for pure $\mathrm{Ti}$ and $\mathrm{Ti}$ 6Al-4V alloy. ${ }^{[38,39]}$ In this case, polyethylene glycol (PEG) was added to partially replace paraffin wax (PW), because PEG has a better wettability than PW and a lower decomposition temperature. Those authors report that the binder contains 63 wt pet PW, 12 wt pet PEG, 14 wt pet PE, 10 wt pet PP, and 1 wt pet stearic acid. A very high solid loading of 72 vol. pet was achieved because of improved compatibility and flowability. Thermal debinding in vacuum of $10^{-3} \mathrm{~Pa}$ resulted in a good control of oxygen $(0.26 \mathrm{pct})$ and carbon (0.095 pct). The sintered parts also showed good shape retention and minimal dimensional deviation. As a consequence of low oxygen and carbon concentrations, the as-sintered samples demonstrated mechanical properties comparable with the wrought alloys (see Table II).

Similar results have been reported by Tijet, a German company. Using a wax-based binder system, ${ }^{[41,42]}$ Tijet was capable of producing engineering components such as bone screws for medical implants from Ti-6Al-4V and Ti-6Al-7Nb with mechanical properties equivalent to those of wrought alloys. Tijet claimed that the following properties can be achieved for Ti-6Al-4V parts (impurity contents: 0.2 pct $\mathrm{O}, 0.05$ pct $\mathrm{C}$, and 0.018 pct $\mathrm{N}$ ): sintered density: $>97$ pct, elongation: 15 pct, yield strength: $700 \mathrm{MPa}$, and tensile strength: $800 \mathrm{MPa}$.

The wax component in wax-based binder systems is used to wet the metallic powder particles while the

Table II. Comparison of Ti-6Al-4V Alloy Made by MIM and Conventional Press-and-Sinter Process ${ }^{[38,40]}$

\begin{tabular}{|c|c|c|c|c|c|}
\hline Process & $\begin{array}{l}\text { Relative } \\
\text { Density }\end{array}$ & $\begin{array}{c}\text { Tensile } \\
\text { Strength }(\mathrm{MPa})\end{array}$ & $\begin{array}{c}\text { Yield } \\
\text { Strength (MPa) }\end{array}$ & $\begin{array}{l}\text { Elongation } \\
\text { (Pct) }\end{array}$ & $\begin{array}{c}\text { Reduction } \\
\text { in Area (Pct) }\end{array}$ \\
\hline $\begin{array}{l}\text { MIM-traditional } \\
\text { binder }(\mathrm{PW} / \mathrm{PE} / \mathrm{PP} / \mathrm{SA})\end{array}$ & $>95 \mathrm{pct}$ & 720 & 645 & 3.0 to 4.5 & 6 \\
\hline $\begin{array}{l}\text { MIM-improved } \\
\text { binder }(\mathrm{PW} / \mathrm{PEG} / \mathrm{PE} / \mathrm{PP} / \mathrm{SA})\end{array}$ & 97 pct & 800 to 835 & 715 to 748 & 5.5 to 9.2 & 15 \\
\hline $\begin{array}{l}\text { MIM-improved binder } \\
\quad(\mathrm{PW} / \mathrm{PEG} / \mathrm{PE} / \mathrm{PP} / \mathrm{SA})+\mathrm{HIP}\end{array}$ & $\sim 99.8$ pct & 1030 to 1060 & 910 to 960 & 9.5 to 12 & 21 \\
\hline Press-and-sinter & 95 to 99 pct & 896 & 827 & 12 & 20 \\
\hline $\begin{array}{l}\text { Wrought alloy } \\
\text { (ASTM-B348 Grade 5) }\end{array}$ & $100 \mathrm{pct}$ & 895 & 828 & 10 & 25 \\
\hline $\begin{array}{l}\text { PM (ASTM-B817, Type } 1 \text {, } \\
\text { Grade } 2 \text { Class B) }\end{array}$ & 99 pct & 958 & 862 & 13 & 29 \\
\hline
\end{tabular}


Table III. PW-Based Binder Systems Used in Ti-MIM

\begin{tabular}{|c|c|c|c|}
\hline Major component & 2nd Component & 3rd Component & Refs. \\
\hline Paraffin wax + carnauba wax & $\mathrm{PP}+\mathrm{EVA}$ & dioctyl phthalate (DOP) & {$[48,49]$} \\
\hline Paraffin wax & PE + PMMA & stearic acid & [50] \\
\hline Paraffin wax + carnauba wax & $\mathrm{PP}$ & & {$[43]$} \\
\hline Paraffin wax & $\mathrm{PEG}+\mathrm{PE}$ & stearic acid & {$[51]$} \\
\hline Paraffin wax & $\mathrm{PE}$ & stearic acid & [42] \\
\hline Paraffin wax + carnauba wax & Atactic PP & stearic acid & {$[52]$} \\
\hline Paraffin wax & $\mathrm{PP}+\mathrm{EVA}+\mathrm{PE}$ & stearic acid & [46] \\
\hline Paraffin wax & $\mathrm{PP}+\mathrm{PE}+\mathrm{PEG}$ & stearic acid & [39] \\
\hline Palm oil & $\mathrm{PE}$ & & [53] \\
\hline
\end{tabular}

polymeric component provides sufficient green strength. Waxes, such as PW, beeswax, carnauba wax (CW), and several wax-like short oligomers or low molecularweight polymers, such as PE or PP, are a class of chemicals which are plastic near ambient temperatures. PE waxes are obtained by cracking high molecularweight $\mathrm{PE}$ at $673 \mathrm{~K}\left(400{ }^{\circ} \mathrm{C}\right)$. They have the formula of $\left(\mathrm{CH}_{2}\right)_{n} \mathrm{H}_{2}$, where $n$ ranges from 50 to 100 ; however, PE and PP waxes are not commonly used in the PIM/MIM industry. The oxygen-containing waxes, such as beeswax and $\mathrm{CW}$, are a potential source of contamination. ${ }^{[43]}$ In contrast, paraffin wax (PW) is a widely accepted choice. The PWs are hydrocarbonaceous mixtures of alkanes (straight carbon chains), having chain length ranging from $\mathrm{C} 20$ to $\mathrm{C} 40$ and melting point ranging from $325 \mathrm{~K}$ to $347 \mathrm{~K}\left(52{ }^{\circ} \mathrm{C}\right.$ to $\left.74^{\circ} \mathrm{C}\right)$. They have consistent chemical structures and thus consistent rheological properties, which are important for consistency and reproducibility of the product quality. Also PWs are more cost effective than other waxes. In a wax-based binder system, the popular backbone polymers are PE, PP, EVA, and high molecular-weight PMMA. Rhee et al. ${ }^{[4]}$ claimed that EVA with low vinyl acetate content was the best MIM binder, based on a great improvement in binder performance in both injection molding and thermal debinding. Additionally, EVA results in an improved feedstock homogeneity, stability, and shape retention during debinding. ${ }^{[44]}$ In comparison with EVA, PP, and HDPE show poor adhesion to the metallic powder, PP being the worst. ${ }^{[4]}$ However, German claimed that a binder system containing PW, $\mathrm{PP} / \mathrm{PE}$, and stearic acid is one of the best binder systems for Ti-MIM. ${ }^{[46]}$ Besides wax and backbone polymers, the binder system often consists of a surfactant which acts as a plasticizer, thereby improving the chemical compatibility between metal powders and polymers. In some cases, other minor additives, such as antioxidants, are also included. The commonly used PW-based binder systems in Ti-MIM are collated by Froes ${ }^{[47]}$ and German ${ }^{[1,15]}$ and listed in Table III. It has been claimed that these binders are compatible with titanium powders. $[11,15]$

In recent years, there have been reports on using vegetable oil as a possible alternative binder system. For instance, Ibrahim et al. ${ }^{[53]}$ reported the use of palm stearin for many binders, which consists of a fatty acid that is used as a surface active agent. The selection of palm stearin as a possible alternative binder system fulfills an important criterion of a binder system in the
PIM process, as its components exhibit various melting points. The combination of $60 \mathrm{wt}$ pct palm oil and $40 \mathrm{wt}$ pct PE was used as the binder for a Ti-6Al-4V alloy powder. It is noted that the resultant strength and elongation were much lower than those specified in ASTM standard B817, which was because of the presence of $\mathrm{TiC}$ in the product.

\section{POLYOXYMETHYLENE-BASED BINDER SYSTEM}

The emergence of a POM-based binder system, which was first disclosed by a US company, Celanese Corp in $1984^{[54]}$ and practically developed by BASF, has made possible the removal of polymers without the use of any wax or low molecular-weight components. ${ }^{[55]} \mathrm{POM}$ is the major component in the binder system, while PE is usually the backbone component. POM is characterized by its high strength, hardness, and rigidity. In the early 1990s, this binder system was further developed and became more practical with the addition of another immiscible polymer components such as PE, PP, and PMMA and further polymeric modification. ${ }^{[56-61]}$ Based on this binder system and debinding technique, BASF offers a comprehensive production line for PIM, marketed under the trade name of Catamold ${ }^{\circledR}{ }^{[57]}$ Currently, Catamold $^{\circledR}$ feedstock is available for a few materials, mainly low-alloy steels, stainless steels, tool steels, and ceramics. POM-based binders and associated catalytic debinding techniques have been widely used in the European PIM industry for both metal and ceramic powders. ${ }^{[62]}$ Several specifically designed furnaces are commercially available. ${ }^{[63-65]}$

An important characteristic of POM is its strong sensitivity to acid hydrolysis by acidic agents. Because of this, the POM in the powder feedstock is removed by treating the green parts in a gaseous acid-containing atmosphere such as nitric acid or oxalic acid, at a temperature well below its softening temperature. As such, the debinding is carried out in the solid state and hence avoids the cracks and bloating that is caused by boiling of the binder. ${ }^{[66]}$ The gaseous catalyst does not penetrate the polymer, and hence the decomposition proceeds only at the gas/binder interface. The planar debinding interface front advances throughout the entire compact, wiping out the entire POM polymer. In this regard, gas exchange is limited to the already formed porous shell and a buildup of internal pressure is 
avoided. Therefore, very little distortion, good shape retention, and precise dimensional control are achievable. $^{[67]}$ In addition, shorter debinding times are achieved with the use of catalysts, as the diffusion rate of the monomer with smaller-sized molecules is much higher. A significantly faster thermal debinding rate (10 times faster) was reported for the catalytic debinding, as compared with other debinding techniques. ${ }^{[68,69]}$ This process also allows thick part sections to be debound. ${ }^{[70]}$ It was claimed that no contamination to the final products after sintering was possible. ${ }^{[54]}$ In a disclosed patent ${ }^{[71]}$ ceramic powders of 54 vol. pct solid loading were formulated with the POM-based binder. Under the debinding atmosphere of $\mathrm{BF}_{3}$ and $\mathrm{N}_{2}$, the binder removal of 4-mm-thick tensile bars was completed in 35 minutes, and the debound bars showed no sag.

However, there are some limitations with regard to the use of catalysts and their contents, due to health concerns. POM decomposes into formaldehyde which because of its toxicity must be controlled under certain concentration limit in the working environment $(20 \mathrm{mg} /$ $\left.\mathrm{m}^{3}\right) .{ }^{[72]}$ The problem with formaldehyde emission can be solved by a two-step burning process. ${ }^{[73]}$ The second issue around the catalytic-debinding process is that it requires significant capital investment on debinding furnaces and associated equipment.

It is important to note that the POM-based binder usually contains a secondary backbone component, most commonly a thermoplastic polymer. Therefore, a thermal debinding step is still needed prior to sintering. With regard to the application of catalytic debinding to Ti-MIM, BASF does provide a Catamold-Ti datasheet, ${ }^{[74]}$ which unfortunately shows a much higher interstitial content than that specified in the ASTM standards. To the best of our knowledge, there are no technical reports on using Catamold-Ti feedstock in the open literature.

\section{AROMATICS-BASED BINDER SYSTEM}

In order to rapidly and completely remove the binder before sintering, sublimation is considered to be an efficient debinding method. In general, sublimation is a process of transformation directly from the solid phase to the gaseous phase without passing through an intermediate liquid phase. Sublimation is commonly used in the separation and purification of chemical substances, under reduced pressures. In the 1960s, naphthalene was used as a binder component for ceramic injection molding. ${ }^{[7]}$ Recently, Weil et al. ${ }^{[76,77]}$ in the Pacific Northwest National Laboratory claimed a binder formulation for a Ti-MIM process, in which an aromatic compound is used both as binder and solvent, and therefore, only a small fraction of the traditional binder materials is required as a minor additive. The main advantage of aromatics such as naphthalene, anthracene, and pyrene is that they melt at relatively low temperatures and can be completely removed from the green parts by sublimation under reduced pressure at temperatures well below their melting points. In Weil et al.'s study, ${ }^{[76,77]}$ naphthalene, stearic acid, and EVA

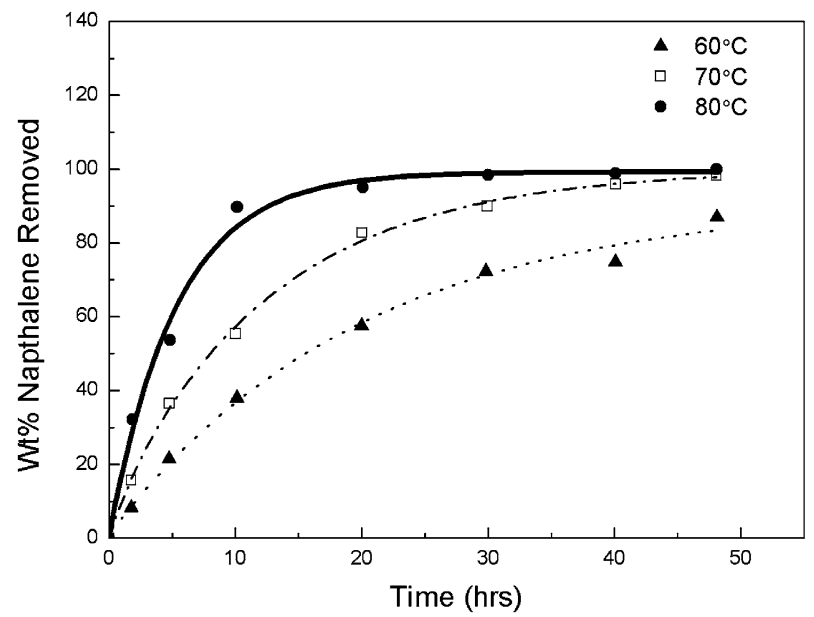

Fig. 6-Debinding behaviors of the MIM Ti-6Al-4V bars. The binder used to formulate the feedstock of 65 vol. pct Ti-6Al-4V powder loading consisted of naphthalene with 6 vol. pet EVA and 1 vol. pct stearic acid, redrawn from Refs. [76,77] with permission.

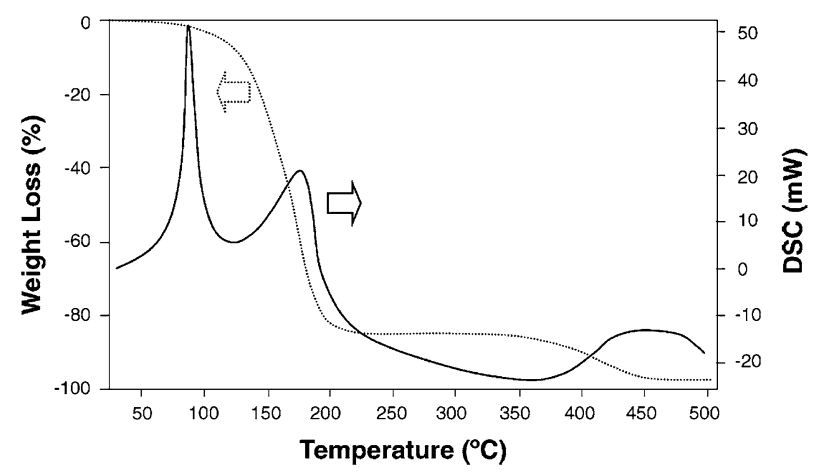

Fig. 7-TGA weight loss and DSC curve for the binder used to formulate the feedstock of 65 vol. pct Ti-6Al-4V powder loading. The binder consisted of naphthalene with 6 vol. pct EVA and 1 vol. pct stearic acid. Reprinted from Refs. [76,77] with permission.

were chosen to formulate a Ti-6Al-4V feedstock. The binder formulation consisted of naphthalene, 1 vol. pct stearic acid, and from 3 to 12 vol. pct EVA. Upon heating to $363 \mathrm{~K}\left(90^{\circ} \mathrm{C}\right)$, the EVA and stearic acid completely dissolve into molten naphthalene resulting in a transparent solution. 50 to 70 vol. pct Ti-6Al-4V powder could be formulated in this binder. Figure 6 presents the debinding result, showing that sublimation for 20 hours at $353 \mathrm{~K}\left(80^{\circ} \mathrm{C}\right)$ was able to completely remove naphthalene, if the debinding is done under a vacuum of $2.67 \mathrm{~Pa}$. EVA is thermally removed in a subsequent debinding step, which is carried out at a temperature ranging from $633 \mathrm{~K}$ to $723 \mathrm{~K}\left(360{ }^{\circ} \mathrm{C}\right.$ to $450{ }^{\circ} \mathrm{C}$ ) (Figure 7). As expected the specimen volume remains constant throughout the debinding process. Unlike solvent evaporation, sublimation involves low surface energies in the vaporization process. This means that common debinding problems such as part distortion and cracking can be avoided by means of the naphthalene-based binder. Furthermore, Weil et al. ${ }^{[76,77]}$ claimed that there is no contamination on titanium powders. Under this debinding technique, the sintered parts show an average density of $4.36 \mathrm{~g} / \mathrm{cm}^{3}$. Also, no 


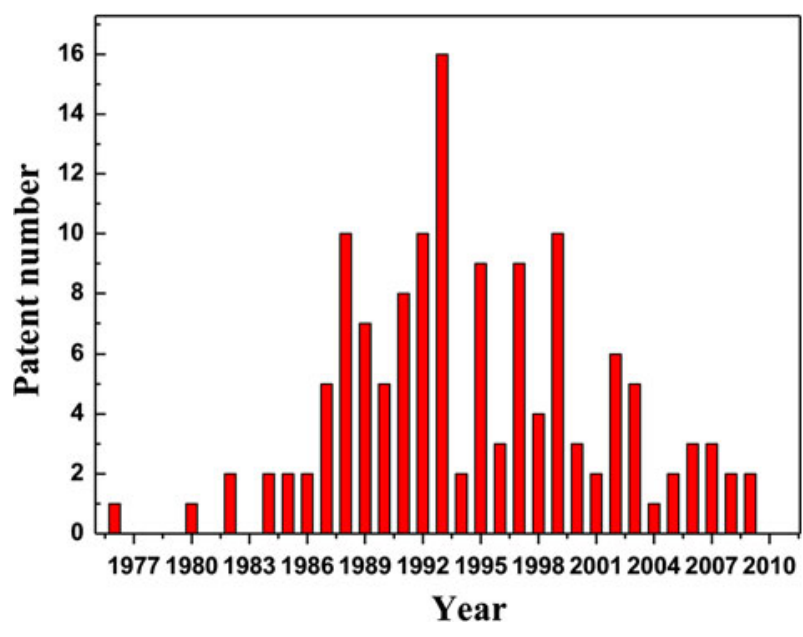

Fig. 8-The number of patents relating to water-soluble binders for PIM since 1970. The majority of patents were granted between the late 1980s and the late 1990s. Source: European Patent Office.

carbon pickup was observed in the sintered parts (217 ppm in the sintered parts $\mathrm{cf} .210 \mathrm{ppm}$ in raw material). However, there are no further reports to follow up on this binder system, probably because of the health and environmental concerns with the toxic aromatic compounds.

\section{WATER-SOLUBLE BINDER SYSTEMS}

Conventional wax-based binders have been widely used in the PIM. However, in order to extract the wax from the green parts, organic solvents must be involved, such as heptanes and hexanes. The use of these solvents causes toxicologic and environmental concerns and necessitates the development of new environmentally friendly binders that are extracted by an environmentally friendly solvent such as ethanol and water. Water-soluble binders which can be removed by an environmentally friendly solvent, such as ethanol and water, have received increasing interest in recent years. The first water-soluble binder, methylcellulose or polyvinyl alcohol (PVOH), was disclosed in $1976 .{ }^{[78,79]}$ Since then, over 130 patents of water-soluble binders were granted in the PIM field, as shown in Figure 8.

Depending on the interaction of the binder component and water, water-soluble binders can be divided into two sub-groups: gelation based and non-gelation based. For the case of non-gelation-based binders, feedstock formulation does not need water. Rather, water is used as an extraction medium during the debinding step. In this category, the commonly used water-soluble synthetic polymers include PEG or polyethylene oxide (PEO, equivalent to PEG with molecular weight higher than 20,000), and PVOH. The nongelation binders are removed by soaking the green parts in the water. On the other hand, the gelation-based binders involve solvents when formulating the feedstock: water being the most common one, but others like glycerol also possible. Gelling - a process in which the binder interacts with water molecules to form gelsoccurs either before or during feedstock formulation. Sometimes, feedstock compounding and injection molding are combined in one step. After injection molding, the green parts are initially dried to remove the water. Subsequently, the remaining portions (polymers and other additives) are removed by thermal debinding. In common cases, thermal debinding and sintering are combined into one single step. Most gelation-based binders are natural polymers which include, for example, polysaccharides ${ }^{80]}$ (such as cellulose, starch, and agar) and polyamino acids (such as proteins). Some synthetic polymers, such as PEG, PVOH, and poly acrylic acid (PAA) ${ }^{[81,82]}$ can also be used as gelationbased binder as well, and they form gels by either physical or chemical bonding under certain conditions.

\section{A. Non-Gelation Based Synthetic Polymers}

Among the non-gelation synthetic polymers, PEG is most commonly used binder component because of its performance and commercial availability. PEGs are soluble in water at a relatively low temperature, nontoxic and have a simple structure, $-\left(\mathrm{CH}_{2} \mathrm{CH}_{2} \mathrm{O}\right)_{n}{ }^{-}$. Depending on the molecular weight $(<10,000)$, PEGs are in the state of either liquid or low-melting-point solid at room temperature. This indicates that PEGs are very similar to wax. PEGs with low molecular weight can be rapidly and near-completely removed in water at up to $333 \mathrm{~K}$ $\left(60{ }^{\circ} \mathrm{C}\right)$. The molecular weight of PEG used in formulating PIM feedstock is usually in the range of 500 to 2000.

In PEG-based binders, PMMA, with a molecular weight of about 1,000,000, is often chosen as the backbone polymer component. Research on MIM using a PEG/PMMA binder was first reported in $1992,{ }^{[83]}$ and it was observed that after solvent debinding, the green parts remained rigid and had excellent shape retention, and sintering shrinkage was uniform and isotropic. Subsequently in 1995, Davies and co-workers ${ }^{[84,85]}$ carried out a similar study on a PEG/PMMA binder system for stainless steel and ceramic powders. The successful use of PEG binders in Ti-MIM has been recorded in the recent years. ${ }^{[86-89]}$ For example, Sidambe et al. ${ }^{[88]}$ reported that $\mathrm{Ti}-6-\mathrm{Al}-4 \mathrm{~V}$ alloy parts were injection molded with 69 vol. pct solid loading by using PEG/PMMA/SA (ratio: 87:11:2 wt. pct). PEG was completely removed by distilled water at $328 \mathrm{~K}\left(55^{\circ} \mathrm{C}\right)$ after 5 hours (Figure 9), and PMMA was removed at temperatures lower than $713 \mathrm{~K}\left(440{ }^{\circ} \mathrm{C}\right)$ by thermal debinding under flowing argon. The thermal debinding of PMMA was verified by thermal gravity analysis (TGA), as shown in Figure 10 which did not record any weight loss for the brown part after thermal pyrolysis. The oxygen content in the sintered samples was approximately 0.20 pct. The attendant tensile strength and elongation ranged from 850 to $880 \mathrm{MPa}$ and 8.5 to 16 pct, respectively, and met the specifications of ISO 5832 and ASTM standards (Grade 5). A similar study on commercial purity Ti was recently carried out in the same group. ${ }^{[89]}$

Most of the non-gelation synthetic polymeric binder systems are proprietary protected.$^{[90-92]}$ There are a few 


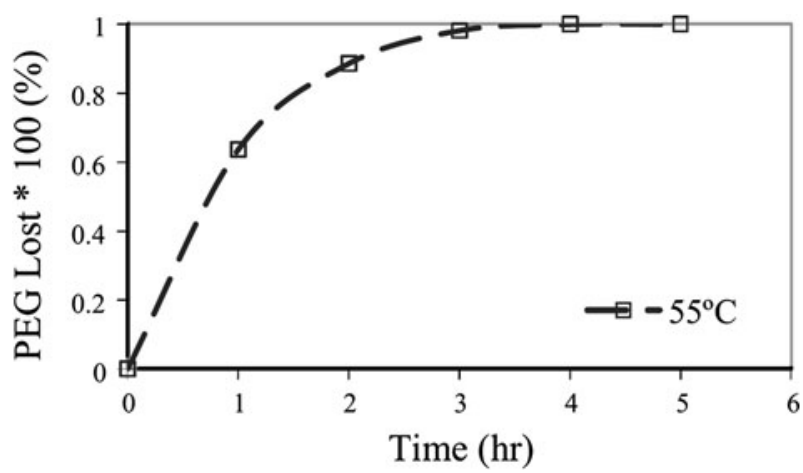

Fig. 9- The removal of PEG from the tensile bars as a function of leaching time in water at $328 \mathrm{~K}\left(55^{\circ} \mathrm{C}\right)$. The Ti or Ti-6Al-4V feedstocks with 69 pct solid loading contained PEG/PMMA/stearic acid at weight ratios of 87:11:2. Reprinted from Ref. [89] with permission.

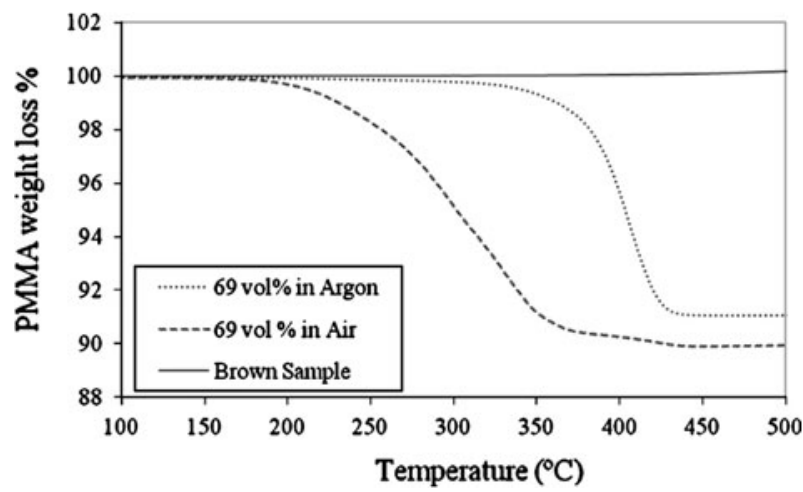

Fig. 10-TGA traces for PMMA in Ti-6Al-4V feedstock. The brown part did not show any weight loss suggesting a complete thermal debinding. For the purpose of comparison, the TGA traces for Ti-6Al-4V feedstock before thermal debinding are also shown. TGA analyses were conducted at a heating rate of $5 \mathrm{~K} / \mathrm{min}$ in argon and in air, respectively. Reprinted from Ref. [89] with permission.

feedstock suppliers of water-soluble binders commercially available in the market. For instance, polyMIM GmbH, a German company, supplies commercial PEGbased stainless steel and titanium feedstocks.

The water-debinding process for water-soluble, nongelation synthetic binders is easier to control, and the debinding equipment is cheaper than for other debinding processes. Nevertheless, disposal of the bindercontaminated waste water would add an extra cost to the MIM process, although the binder used is biologically degradable and nontoxic to microorganisms. ${ }^{[93]^{\circ}}$

\section{B. Gelation-Based Polymers}

Most gelation-based polymers are natural polymers. These natural polymers have wide applications in the binder and adhesive industry, as they are "natural" products and environmentally friendly, abundant, and ready-to-use. Water-soluble natural polymers such as polysaccharides and proteins were recognized as potential binders for MIM processes a few decades ago ${ }^{[94-96]}$ and have still received much attention in recent years. ${ }^{[80]}$ Among the natural polymers, cellulose, starch, and agar are the most studied polysaccharides. Owing to the

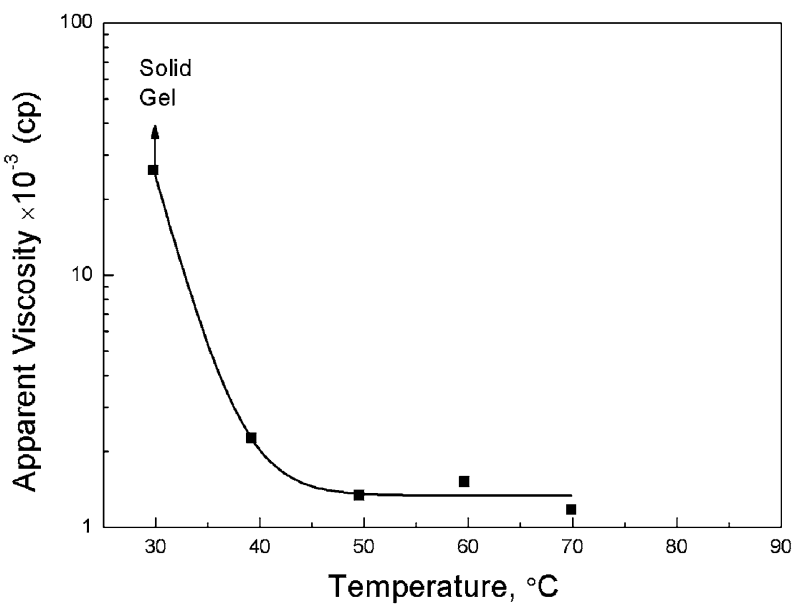

Fig. 11-Viscosity of agar as a function of temperature. Reprinted from Ref. [94] with permission.

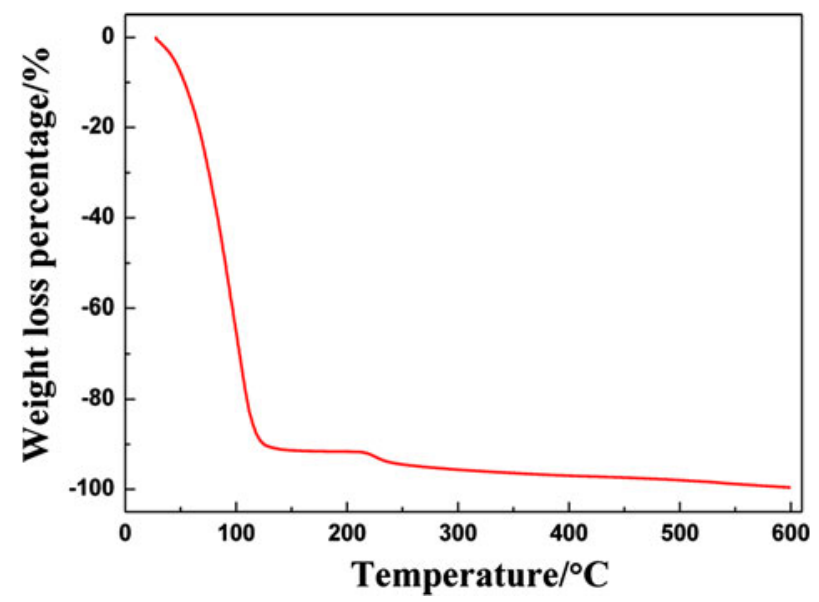

Fig. 12-TGA trace of the $2 \mathrm{wt}$ pct agar-2 wt pct sucrose gel binder.

unique viscosity and strength change with temperature, shown in Figure 11, agar and its derivatives have been attracting much attention. ${ }^{[94,97]}$ Chemically, agar is a polymer made up of subunits of the sugar galactose; it is a component of the algae's cell walls. When dissolved in hot water and cooled, agar becomes gelatinous. In 1988, an injection molding process using agar as an aqueous binder was developed by Fanelli et al., and a patent was granted in the USA. ${ }^{[97]}$ Further development reveals that a gel-strengthening additive is necessary for agarbased binder systems. This additive could be sodium borate ${ }^{[98]}$ sodium silicate,${ }^{[99]}$ the mixture of an acid and a base, ${ }^{[100]}$ or sugar. ${ }^{[101]}$ The optimum molecular weight of agar ranges from 30,000 to $150,000,{ }^{[102]}$ as too high a molecular weight makes agar difficult to decompose by heating. The agar-based binder systems are applicable to both ceramic and metallic powders. Tokura et al. ${ }^{[103]}$ employed agar to replace a polymeric binder in Ti-MIM and investigated the thermal stability, solubility, and viscosity of the feedstock. As with wax in the wax-based binder, water in agar serves as the fluid medium and amounts to approximately $50 \mathrm{vol}$. pet of the binder 


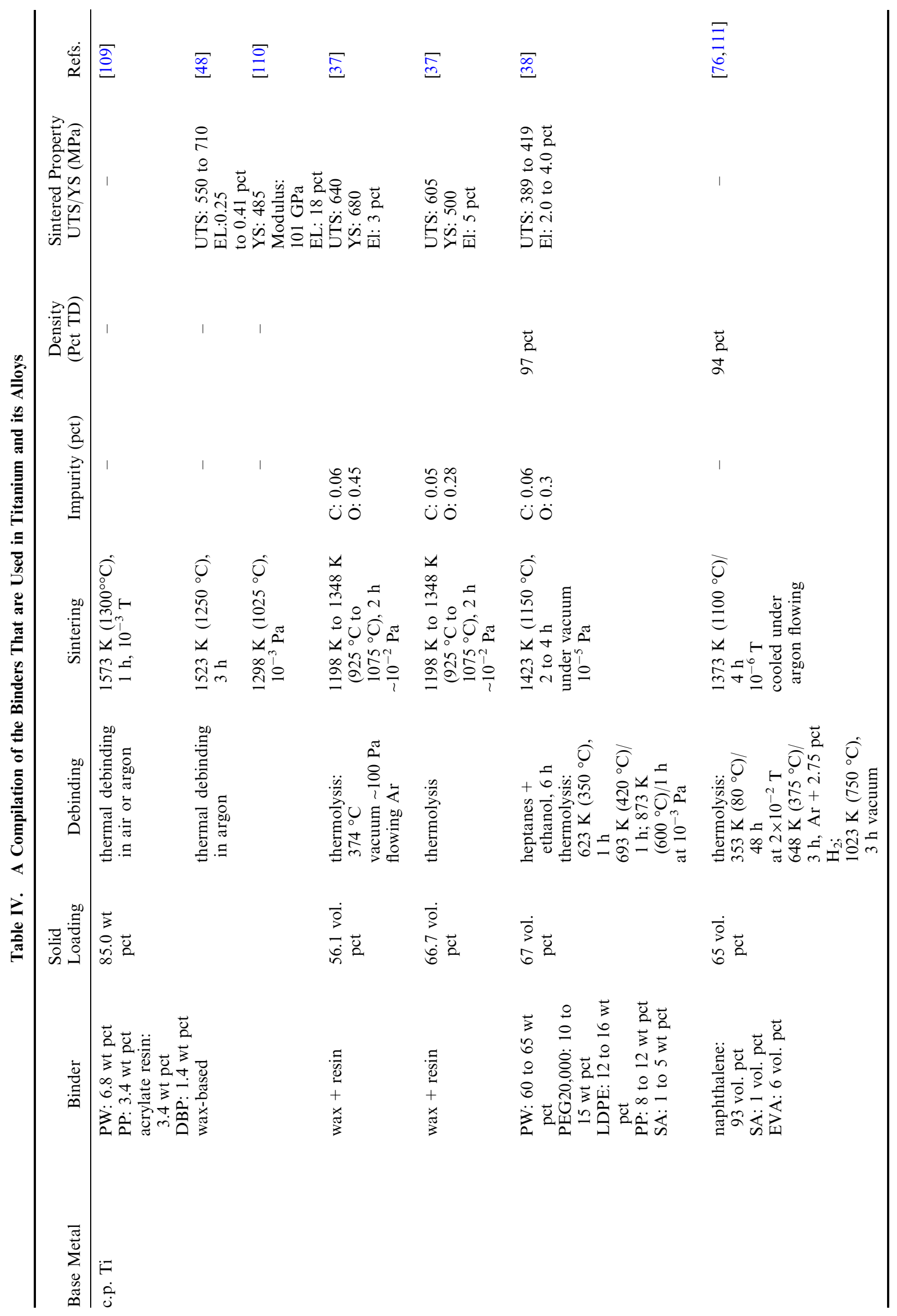




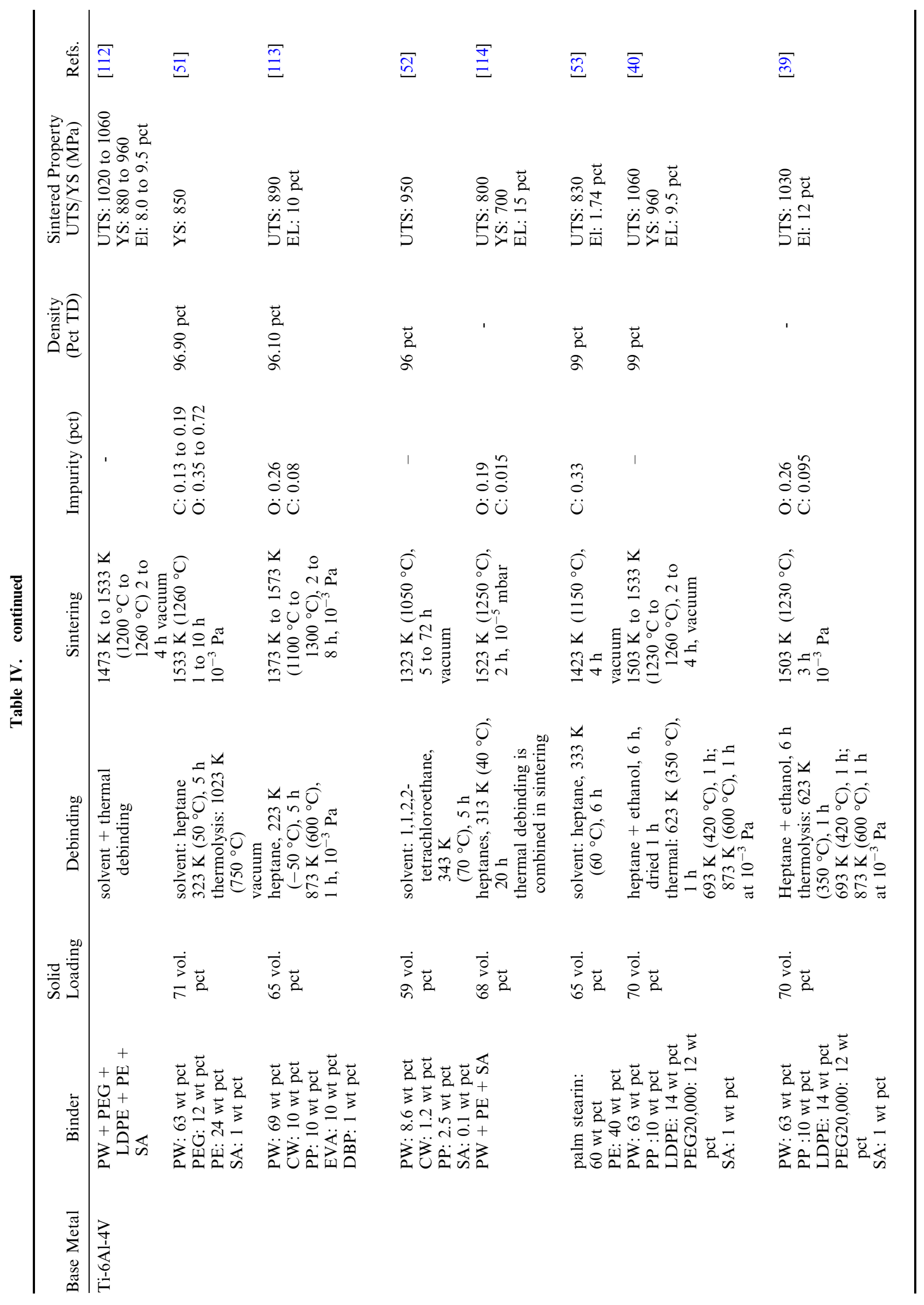

METALLURGICAL AND MATERIALS TRANSACTIONS A 


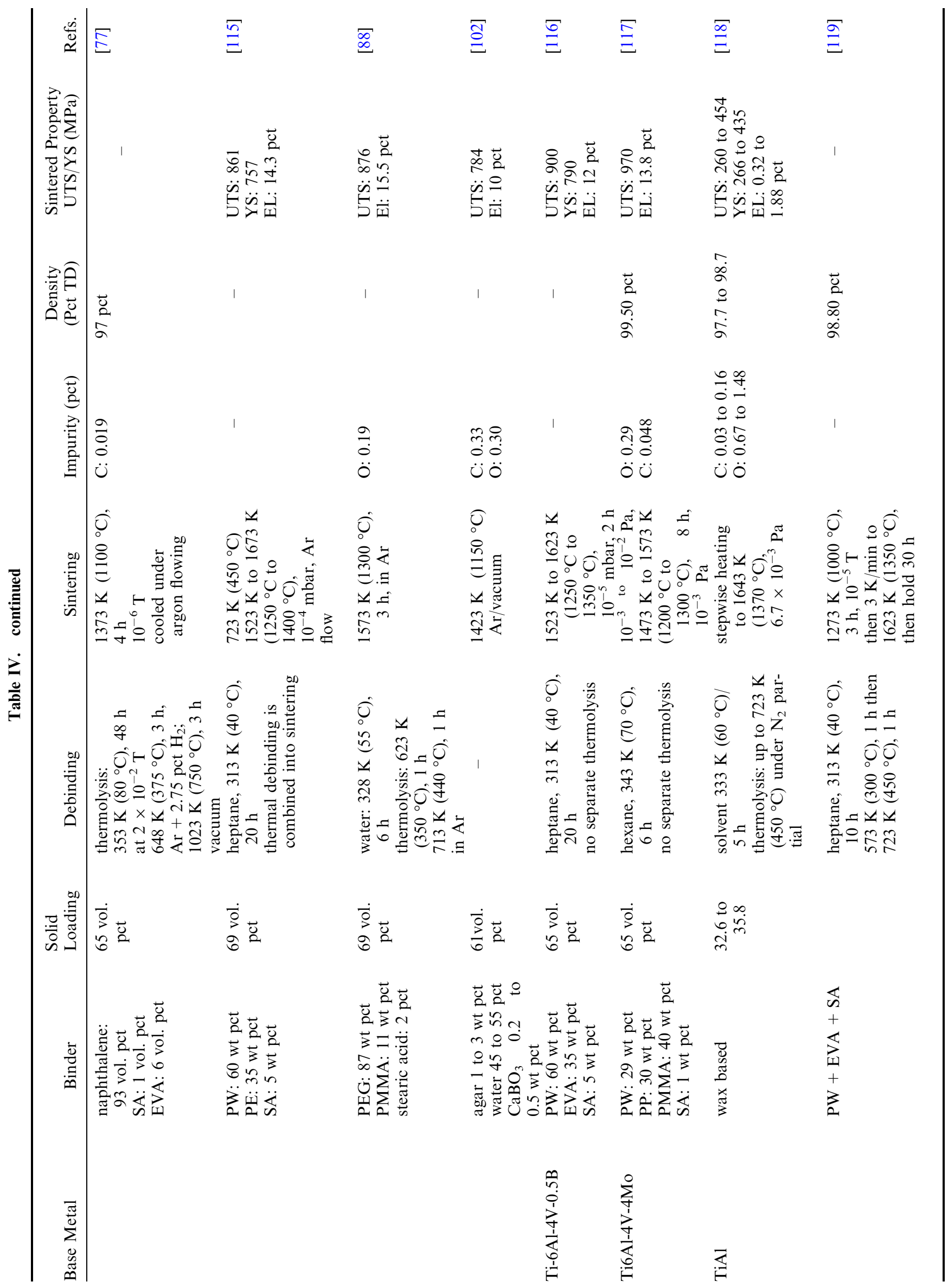




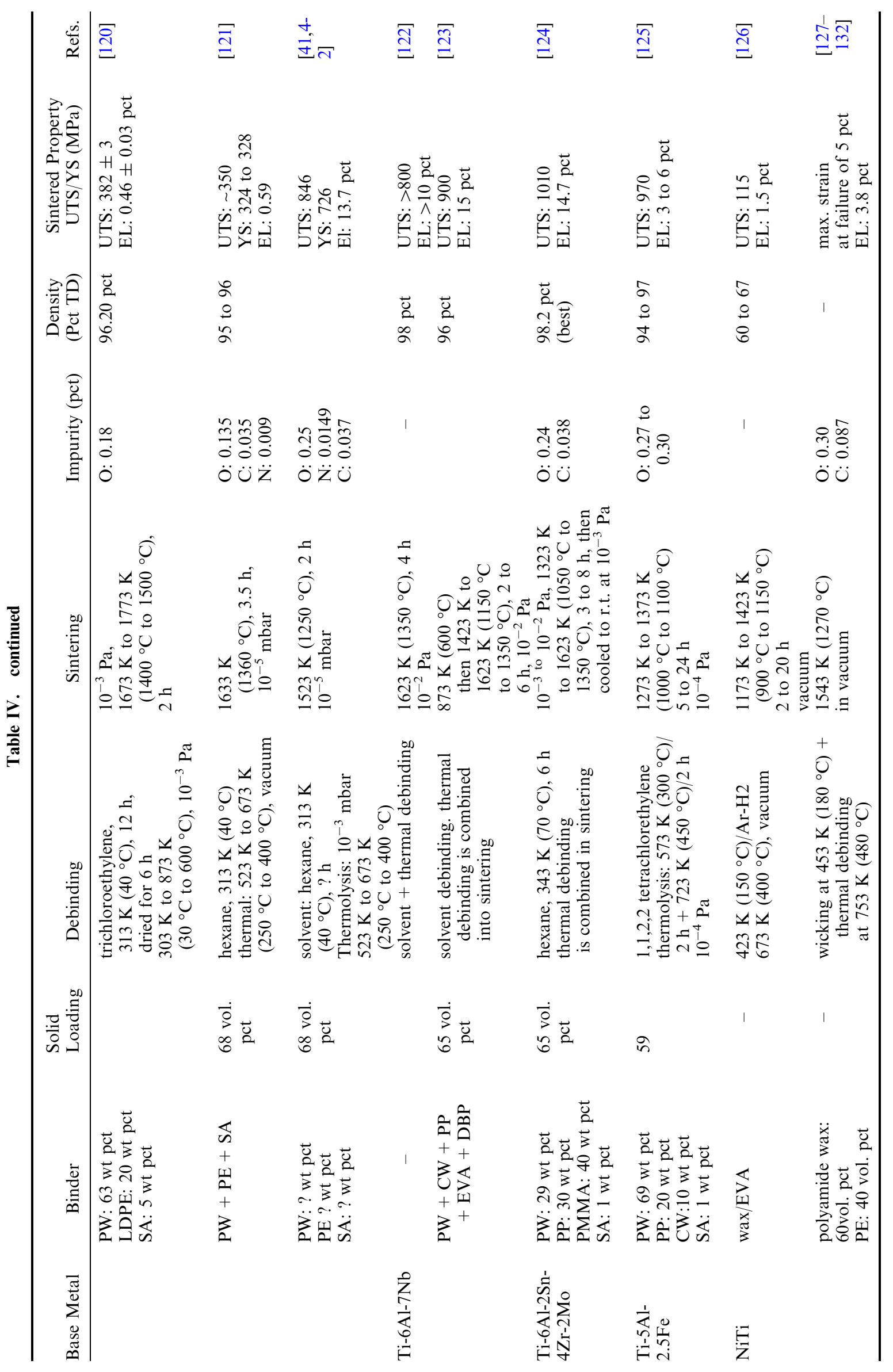




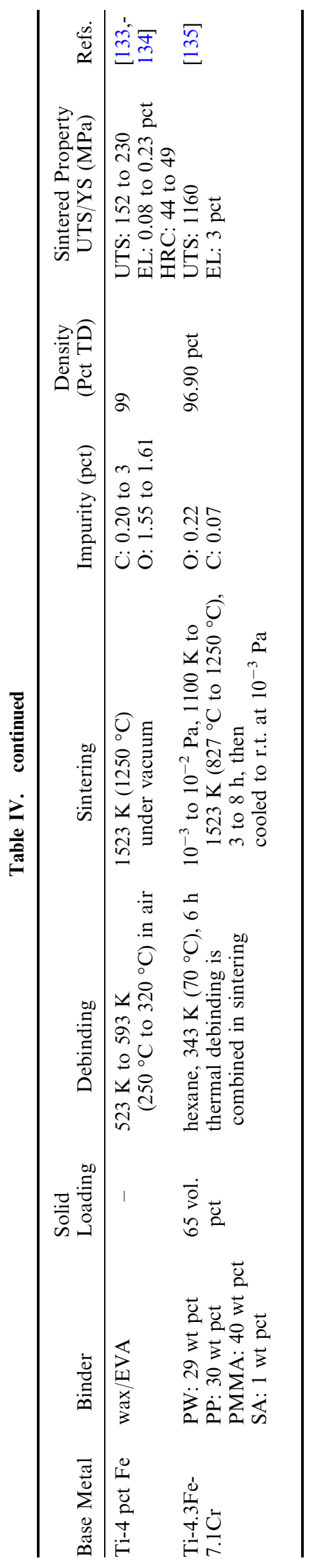

system. Agar provides the "setting" function for the molded part. The agar molecules form a gel network with open channels in the part, allowing easy removal of the water by evaporation. The time required to remove completely agar and water in debinding is much less than for the wax-based binders. In a recent study, we formulated a feedstock using an agar-based binder that consisted of $2 \mathrm{wt}$ pct agar, $2 \mathrm{wt}$ pct sucrose, and $96 \mathrm{wt}$ pct water. The feedstock contained 60 vol. pct solid loading. The thermogravimetric analysis (TGA) trace for the binder is shown in Figure 12, from which the water is removed by evaporation, while the remaining chemicals are burnt out. A total weight loss of $99.6 \mathrm{pct}$ is achieved at $873 \mathrm{~K}\left(600{ }^{\circ} \mathrm{C}\right)$.

Processing with the water-soluble polysaccharides leads to success in general and is mainly attributable to the avoidance of thermal burnout at relatively high temperatures. Nevertheless, the use of the polysaccharides is not free from problems. First, polysaccharides are costly, which significantly adds to the cost of the final product. Second, the low gelling temperature [308 $\mathrm{K}$ to $312 \mathrm{~K}\left(35^{\circ} \mathrm{C}\right.$ to $\left.39^{\circ} \mathrm{C}\right)$ of an agaroid binder system prolongs the molding cycle time, which adversely affects the production rate. To circumvent these issues, Behi $^{[104]}$ developed a low-cost gel-forming binder that consists from 1 to $5 \mathrm{wt}$ pct hydrated carrageen and several gel-strengthening additives, such as $\mathrm{LiCl}, \mathrm{NaCl}$, $\mathrm{KCl}$, maltose, mannose, glucose, raffinose, and ribose. The use of this new binder significantly reduces the molding cycle time by 25 pct and the cost of the binder by 33 pct. This binder also allows for a direct compounding/molding technique, which eliminates the use of a twin screw machine for the feedstock.

Metal Powder Report (MPR) reported the application of an agar-based binder in production of titanium alloy dental implants. ${ }^{[105]}$ The binder system contained from 2 to $3 \mathrm{wt}$ pct agar, a gel-strengthening borate compound, and $18 \mathrm{wt}$ pct water. Biocides may be used to inhibit bacterial growth in the molding compositions, particularly, if they are to be stored for a long period of time. No separate debinding step is required, as it is incorporated into the first one-hour cycle of the sintering (presintering) process. During the pre-sintering step, the binder pyrolyzes in the furnace, and carbon is typically removed with a protective argon atmosphere. Suzuki et al. ${ }^{[102]}$ have sintered pure Ti parts made by Ti-MIM using agar-based binder system containing 4wt pct agar with a molecular weight of 82,500 . A sintered density equivalent to 97.3 pct of theoretical density was obtained with carbon and oxygen contents being 0.33 pct and $0.30 \mathrm{pct}$, respectively. The reported yield strength, tensile strength, and elongation were $539 \mathrm{MPa}, 784 \mathrm{MPa}$, and 10 pct, respectively. When using an agar with a high molecular weight and high gel strength, the sintered $\mathrm{Ti}$ parts had a lower sintered density, lower tensile strength, and much lower elongation (i.e., 3 pct), ${ }^{[102]}$ which are contributed by much higher carbon and oxygen contents. In comparison with the ASTM specifications, Suzuki et al.'s results are far below the standards.

A disadvantage of a gelation-based binder is the dimensional control of the final parts. Also in this system, water is a substantial portion, and evaporation 
of water during mixing and molding can significantly change the composition of the feedstock and green parts, which in turn creates difficulties for processing and quality control. Although a separate debinding step is not required, a long drying time is usually necessary for water-based binder systems.

\section{DESIGN STRATEGIES AND FUTURE DEVELOPMENT}

The key issue around titanium powder metallurgy in general, and Ti-MIM in particular, is the impurity control. A great deal of efforts have been devoted to the development and design of specialty furnaces for MIM debinding and sintering, and a variety of debinding and sintering furnaces are available on the market. ${ }^{[106,107]}$ Nevertheless, the impurity levels in the starting titanium or titanium alloy powders gives very limited margin for tolerating impurity pickup from binder materials and/or powder handling, debinding, and sintering processes. For example, if a titanium powder produced using a hydrogenation and dehydrogenation (HDH) process is used, the powder normally contains 0.25 to $0.35 \mathrm{wt}$ pet oxygen already, and for an end product having $0.30 \mathrm{wt}$ pet $\mathrm{O}$ max as per the ASTM B817 standard to be produced, the oxygen pickup from the entire MIM process must be extremely low. Also titanium starts to significantly react with oxygen at a temperature above $873 \mathrm{~K}\left(500{ }^{\circ} \mathrm{C}\right)$. At a typical sintering temperature, titanium is able to dissolve up to $2.25 \mathrm{wt}$ pct oxygen and 0.9 wt pet nitrogen; ${ }^{[108]}$ therefore, impurities left in the debound "brown" parts would dissolve into titanium, causing undesirable properties. In this regard, the first and most important requirement for binders and debinding development is the ease of binder removal at a temperature below $873 \mathrm{~K}\left(500{ }^{\circ} \mathrm{C}\right)$.

There are several major feedstock suppliers who manufacture and sell commercial purity (CP) titanium and Ti-6Al-4V feedstock. Some typical examples of binder systems for Ti-MIM process have been collated in Table IV. However, specialty titanium alloy feedstock is generally unavailable in the market. Furthermore, most of the commercial feedstocks are supplied as a "black box" and they are often trade secrets. For example, most of the polymers, such as PE, PP, and PMMA, have been used as a binder component. Unfortunately some basic information about the polymers used in feedstocks, such as the grade, molecular weight, physical and chemical properties, and thermal and mechanical properties is missing. As such, it is not surprising that there has been a huge difference in performance reported by different researchers even when they were using the same binder.

The binder development should focus on the selection of the backbone components, the most common polymers of which include PE, PP, PMMA, and EVA. These polymers are readily available, inexpensive, well characterized, and well understood. However, they cannot meet all of the binder requirements. For example, they can provide good processability and excellent green strength, but they are difficult to remove thermally because of their high thermal decomposition temperatures. However, it needs to be pointed out that thermal decomposition (pyrolysis or burning) is not the only way to break down the polymer backbones. Polymer degradation can take place chemically, optically (ultraviolet or ultra-short wave rays), mechanically, and/or biologically. The degradable plastics and depolymerization, which is termed "polymer green chemistry", have been receiving extensive interests in recent years. One such example is the use of catalytic depolymerization in the field of waste plastic recycling. ${ }^{[136]}$ In a similar way, such catalytic depolymerization techniques can be used as a new debinding method in Ti-MIM. Nonetheless, developing new types of polymer suitable for Ti-MIM is always encouraged and achievable technically. Polymer, in general, can be designed, synthesized, post-modified, and assembled, with a great degree of freedom. For instance, reversible polymerization or crosslinking can be applied in a Ti-MIM process. In reversible polymerization, a polymer network forms by polymerization or crosslinking under a stimulus such as heat, light, or radiation. If these reversible polymers are used in feedstock formulation, then the crosslinked molecules can revert to the starting monomers or molecules when they are exposed to an external stimulus.

A final but equally important point is a requirement for the development of new debinding technologies. Very often a new debinding process will bring on board more binder options and revolutionize the MIM process. One such example was recently disclosed by Johnson Matthey Co. ${ }^{[137]} \mathrm{Ti}$ metal powders are surface coated by 0.25 wt pet Pd metal in the feedstock and in the shaped bodies, so that at least a proportion of the carbon and/or oxygen is catalytically removed by $\mathrm{Pd}$.

As noted earlier, many demonstration components have been formed using Ti-MIM, and a few companies are providing feedstock. However, as pointed out by German, ${ }^{[8]}$ the market for titanium products by MIM is very small-only 1 pct of the global MIM market, making up about US \$10 million in component sales globally. The total sales turnover for Ti-MIM in 2007were US \$4 million, most of this being for surgical tools (source: the Japan Powder Metallurgy Association). To expand the market percentage, aerospace, medical, and biomedical applications should be considered. It means that the development of Ti-MIM should focus on methods for controlling carbon and oxygen levels to meet the higher standards. The market penetration to high-end products is encouraged by the newly proposed ASTM standard WK35394, and some leading medical device companies are planning to invest on Ti-MIM, e.g., Stryker Instruments. ${ }^{[138]}$ Apart from the selection of the powder production routes and the resulting quality, the binder design and debinding techniques are the main technical issues requiring attention.

\section{REFERENCES}

1. F.H. Froes: Handbook of Advanced Materials, J.K. Weasel, ed., McGraw, New York, 2000. 
2. G. Welsch, R. Boyer, and E.W. Collings: Materials Properties Handbook: Titanium Alloys, ASM International, Materials Park, OH, 1994.

3. J.E. Barnes, W. Peter, and C.A. Blue: Mater. Sci. Forum, 2009, vols. 618-619, pp. 165-68.

4. F.H. Froes and M.A. Imam: Key Eng. Mater., 2010, vol. 436, pp. $1-11$.

5. R.M. German: Powder Injection Molding, Metal Powder Industries Federation, Princeton, NJ, 1990.

6. Y. Kaneko, K. Ameyama, K. Saito, H. Iwasaki, and M. Tokizane: J. Jpn. Soc. Powder Metall., 1988, vol. 35, pp. 646-50.

7. F. Froes: Powder Metall. Met. Ceram., 2007, vol. 46 (5), pp. 303-10.

8. R.M. German: Int. J. Powder Metall., 2010, vol. 46, pp. 11-17.

9. T. Ebel, C. Blawert, R. Willumeit, B.J.C. Luthringer, O.M. Ferri, and F. Feyerabend: Adv. Eng. Mater., 2011, vol. 13 (12), pp. B440-53.

10. F.H. Froes and R.M. German: Met. Powder Rep., 2000, vol. 55 (6), pp. 12-21

11. R.M. German: PIM Int., 2009, vol. 3 (4), pp. 21-37.

12. U.M. Attia and J.R. Alcock: J. Micromech. Microeng., 2011, vol. 21 (4), p. 043001.

13. F.H. Froes: Mater. Technol., 2000, vol. 15 (4), pp. 295-99.

14. F.H. Froes: Met. Powder Rep., 2006, vol. 61 (11), pp. 20-23.

15. R.M. German and A. Rose: Injection Molding of Metals and Ceramics, Metal Powder Industries Federation, Princeton, NJ, 1997.

16. E. Baril: PIM Int., 2010, vol. 4, pp. 22-33.

17. E. Baril, L.P. Lefebvre, and Y. Thomas: Powder Metall., 2011, vol. 54 (3), pp. 183-87.

18. H. Conrad: Prog. Mater Sci., 1981, vol. 26, pp. 123-403.

19. Y. Ikeda, S. Ikeda, and S. Takaki: J. Jpn. Soc. Powder Metall., 1995, vol. 42, pp. 911-17.

20. L.P. Lefebvre and E. Baril: Adv. Eng. Mater., 2008, vol. 10 (9), pp. $868-76$

21. J.A. Grohowski, B.S. Sherman, and J.T. Strauss: Proceedings of the 2003 International Conference on Powder Metallurgy \& Particulate Materials, MPIF, Las Vegas, June 8-12, 2003, pp. 273-81.

22. H. Conrad: Acta Metall., 1966, vol. 14 (11), pp. 1631-33.

23. K. Okazaki and H. Conrad: Acta Metall., 1973, vol. 21, pp. 1117-29.

24. T. Ebel: Proceedings of the $5^{\text {th }}$ International Light Metals Technology Conference, Trans Tech Publications, Lueneburg, July 19-22, 2011, pp. 181-84.

25. ASTM F67-06: Standard Specification for Unalloyed Titanium, for Surgical Implant Applications, 2006.

26. ASTM F136-11: Standard Specification for Wrought Titanium6Aluminum-4Vanadium ELI (Extra Low Interstitial) Alloy for Surgical Implant Applications, 2011.

27. ASTM B348-11: Standard Specification for Titanium and Titanium Alloy Bars and Billets. 2011.

28. ASTM B817-08: Standard Specification for Powder Metallurgy (PM) Titanium Alloy Structural Components, 2008.

29. ASTM F2885-11: Standard Specification for Metal Injection Molded Titanium-6Aluminum-4Vanadium Components for Surgical Implant Applications, 2011.

30. D. Price and A.R. Horrocks: Fire Retardancy of Polymeric Materials, A. Wilkie and A.B. Morgan, eds., CRC Press, Boca Raton, 2010.

31. C.L. Beylerm and M.M. Hirschler: Handbook of Fire Protection Engineering, P.J. DiNenno, ed., SFPE, Boston, 1995, 2nd ed..

32. S.C. Moldoveanu: Analytical Pyrolysis of Synthetic Organic Polymers, Elsevier, New York, 2005, vol. 25.

33. S. Liang, Y. Tang, B. Huang, and S. Li: Trans. Nonferr. Met. Soc. China, 2004, vol. 14 (4), pp. 762-68.

34. K.F. Hens and R.M. German: Proceedings of the 1995 International Conference and Exhibition Powder Metallurgy and Particulate Materials, MPIF/APMI, Seattle, May 14-17, 1995, pp. 6.27-.36.

35. K. Schwartzwalder: US Patent 2122960, 1938.

36. Y. Kaneko, K. Ameyama, and S. Sakaguchi: J. Jpn. Soc. Powder Metall., 1990, vol. 37 (5), p. 605.
37. K. Kato: J. Jpn. Soc. Powder Metall., 1999, vol. 46 (8), pp. 865-69.

38. S. Guo, B. Duan, X. He, and X. Qu: Rare Met., 2009, vol. 28, pp. 261-65.

39. S. Guo, X. Qu, X. Wu, and X. He: J. Mater. Process. Technol., 2006, vol. 173, pp. 310-14.

40. X. Qu, S. Guo, C. Tang, M. Qin, X. He, and S.H. Islam: Mater. Sci. Forum, 2007, vols. 539-543, pp. 2639-44.

41. E. Aust, W. Limberg, R. Gerling, B. Oger, and T. Ebel: Adv. Eng. Mater., 2006, vol. 8, pp. 365-70.

42. W. Limberg, E. Aust, T. Ebel, R. Gerling, and B. Oger: Proceedings of Powder Metallurgy World Congress \& Exhibition, EPMA, Vienna, Austria, 17-21 October, 2004, vol. 4, pp. 457-62.

43. H. Nakamura, T. Shimura, and K. Nakabayashi: J. Jpn. Soc. Powder Metall., 1999, vol. 46, pp. 870-76.

44. B.O. Rhee, M.Y. Cao, H.R. Zhang, E. Streicher, and C.I. Chung: Advances in Powder Metallurgy-Part 2 Powder Injection Molding, Improved wax-based binder formulations for powder injection molding, Chicago, June 9-12, 1991, pp. 43-58.

45. J.M. Adames: Chacterization of polymeric binders for metal injection molding (MIM) process, The University of Akron, 2007.

46. S.J. Park, Y. Wu, F.F. Heaney, X. Zou, G. Gai, and R.M. German: Metall. Mater. Trans. A, 2009, vol. 40A, pp. 215-22.

47. F.H. Froes: Development in titanium PIM., 2007. Available online from: http://www.webs1.uidaho.edu/imap/MPR\%20Paper.pdf.

48. T. Kono, A. Horata, and T. Kondo: J. Jpn. Soc. Powder Metall., 1997, vol. 44, pp. 985-92.

49. K. Kusaka: Proceedings of the 1996 World Congress on Powder Metallurgy and Particulate Materials, MPIF/APMI, Washington, June 16-21, 1996, pp. 19.127-.132.

50. Y. Itoh, T. Hankou, K. Sato, and H. Miura: Proceedings of Powder Metallurgy World Congress \& Exhibition, EPMA, Vienna, Austria, 17-21 October, 2004, vol. 4, pp. 445-450.

51. S. Guo, X. Qu, B. Duan, M. Qin, and Y. Zhang: Rare Met. Mater. Eng., 2005, vol. 34, pp. 1123-27.

52. K. Maekawa, M. Takita, and H. Nomura: J. Jpn. Soc. Powder Metall., 1999, vol. 46, pp. 1053-57.

53. R. Ibrahim, M. Azmirrudin, M. Jabir, M.R. Ismail, M. Muhamad, R. Awang, and S. Muhamad: Am. J. Appl. Sci., 2010, vol. 7, pp. 811-14.

54. G. Farrow and A.B. Conciatori: European Patent EP0114746 A2, 1984.

55. S. Krug, J.R.G. Evans, and J.H.H. ter Maat: J. Eur. Ceram. Soc., 2000, vol. 20 (14-15), pp. 2535-41.

56. J. Benhoech, D. Weinand, W. Kochanek, and M. Bloemacher: US Patent 5362791, 1994

57. M. Bloemacher and D. Weinand: J. Mater. Process. Technol., 1997, vol. 63 (1-3), pp. 918-22.

58. M. Blomacher, D. Weinand, H. Wohlfromn, and J.H.H.t. Maat: US Patent 2003093146, 2001.

59. H.J. Sterzel and J.H.H. ter Maat: US Patent 5198489, 1993.

60. H.J. Sterzel and H. Wohlfromn: US Patent 5604919, 1996.

61. H. Wohlfromn, J. Assmann, H. Henrick, and M. Bloemacher: US Patent 2009/0288739, 2009

62. P.J. Vervoort, R. Vetter, and J. Duszczyk: Adv. Perform. Mater., 1996, vol. 3, pp. 121-51.

63. CMF: available from http://www.cmfurnaces.com.

64. Elnik: available from http://www.elnik.com/.

65. P. Vervoort and I. Cremer: Proceedings of Euro PM 2000: Materials and Processing Trends for PM Components in Transportation, Munich, 18-20 October, 1994, pp. 159-62.

66. S. Krug, J.R.G. Evans, and J.H.H. ter Maat: J. Eur. Ceram. Soc., 2001, vol. 21 (12), pp. 2275-83.

67. G. Fu, N.H. Loh, S.B. Tor, B.Y. Tay, Y. Murakoshi, and R. Maeda: Appl. Phys. A, 2005, vol. 81 (3), pp. 495-500.

68. BASF: Catamold: Imagination is the only limit, $2^{\text {nd }}$ August, 2012. Retrieved from: http://www.basf.com/group/corporate/en/ literature-document: Sales + Products + Catamold + Ti-BrochureCatamold + Imagination + is + the + only + Limit-English.pdf.

69. J. Ebenhoech, J.H.H. ter Maat, and H.J. Sterzel: Proceedings of the 1991 Powder Metallurgy Conference and Exhibition, MPIF/ APMI, Chicago, June 9-12, 1991, vol. 2, pp. 159-161.

70. D.C. Kruger: US Patent 5,531,958, 1996.

71. H.J. Sterzel, J.H.H. ter Maat, J. Ebenhoech, and M. Meyer: US Patent 5145900, 1992 
72. N. Goyer, D. Begin, C. Beaudry, M. Bouchard, G. Carrier, G. Lavoure, N. Noisel, and M. Gerin: Prevention guide-Formaldehyde in the work place, 2006. Available from: www.irsst.qc.ca/ media/documents/PubIRSST/RG-473.pdf.

73. J.M. Torralba, J. Hidalgo, and A. Jimenez-Morales: The 8th International Conference on Industrial Tools and Materials Processing Technologies, Powder Injection Moulding: Processing of Small Parts of Complex Shape, TECOS, Ljubljana, Slovenia, 2-5 October, 2011, pp. 53-58.

74. BASF: Catamold ${ }^{\circledR} T i, 2008$. Available from: http://www.catamold. de/ca/internet/Catamold/en_GB/function/conversions:/publish/ content/Microsite/Catamold/Technische_Informationen_/Produk tdatenblaetter/DataSheet_Catamold_Ti.pdf.

75. E.R. Herrmann: US Patent 3234308, 1966.

76. K.S. Weil, E.A. Nyberg, and K.L. Simmons: Metall. Mater. Trans. A, 2005, vol. 46A, pp. 1525-31.

77. K.S. Weil, N. Eric, and S. Kevin: J. Mater. Process. Technol., 2006, vol. 176, pp. 205-09.

78. R. Ronald: US Patent 4113480, 1976.

79. N. Sarkar and G.K. Greminger: Am. Ceram. Soc. Bull., 1983, vol. 62, pp. 1280-88.

80. H. Abolhasani and N. Muhamad: J. Mater. Process. Technol, 2010, vol. 210 (6-7), pp. 961-68.

81. J.E. Glass: Water-Soluble Polymers in Advances in Chemistry, American Chemistry Society, Washington, DC, 1986, vol. 213.

82. Y. Osada, K. Kajiwara, T. Tanaka, and H. Ishida: Gels Handbook, Elsevier, Amsterdam, 2000.

83. M.Y. Cao, J.W. O'Connor, and C.I. Chung: Proceedings of the 1992 Powder Metallurgy World Congress, APMI, San Francisco, Princeton, 16-21 June, 1992, pp. 85-98.

84. M.Y. Anwar, P.F. Messer, B. Ellis, and H.A. Davies: Powder Metall., 1995, vol. 38, pp. 113-19.

85. H.I. Bakan, Y. Jumadi, P.F. Messer, H.A. Davies, and B. Ellis: Powder Metall., 1998, vol. 41, pp. 289-91.

86. G. Chen, G.A. Wen, P. Cao, N. Edmonds, and Y.M. Li: PIM Inter., 2012, vol. 6, pp. 83-88.

87. G. Chen, G.A. Wen, N. Edmonds, P. Cao, and Y.M. Li: Key Eng. Mater., 2012, vol. 520, pp. 173-80.

88. A.T. Sidambe, I.A. Figueroa, H. Hamilton, and I. Todd: PIM Int., 2010, vol. 4 (4), pp. 54-62.

89. A.T. Sidambe, I.A. Figueroa, H.G.C. Hamilton, and I. Todd: J. Mater. Process. Technol., 2012, vol. 212 (7), pp. 1591-97.

90. K.F. Hens, D.M. Kupp, R.A. Alexander, and K.-H. Schofalvi: US Patent 5332537, 1992.

91. M. Takayama, M. Miyake, and Y. Ohyama: Binder for use in metal powder injection moulding and debinding method by the use of the same, WO 96/25261, 1996.

92. X. Yang and R.J. Petcavich: US Patent 6008281, 1999.

93. S.W. Shalaby, C.L. McCormick, and G.B. Butler: Water-Soluble Polymers: Synthesis, Solution Properties and Applications, American Chemical Society, Washington, D.C., 1991.

94. A.J. Fanelli, R.D. Silvers, W.S. Frei, J.V. Burlew, and G.B. Marsh: J. Am. Ceram. Soc., 1989, vol. 72 (10), pp. 1833-36.

95. R.D. Rivers: US Patent 4113480, 1978.

96. J.E. Schuetz: Am. Ceram. Soc. Bull., 1986, vol. 65 (12), pp. 1556-59.

97. A.J. Fanelli, G.B. March, J.V. Burlew, C.P. Ballard, and W.S. Feri: US Patent 5,250,251, 1993.

98. A.J. Fanelli and R.D. Silvers: Process for injection molding ceramic composition employing an agaroid gell-forming material to add green strength a preform, US Patent 4,734,237, 1988.

99. M. Behi: Stable aqueous iron based feedstock formulation for injection moulding, WO 02/09900, 2002.

100. M. Behi: Improvement of flow characteristics of metal feedstock for injected moulding, WO-02/45889, 2002.

101. M. Behi: PhD Thesis, New Jersey Institute of Technology, New Jersey, 2001.

102. K. Suzuki and T. Fukushima: US Patent 6171360, 2001.

103. H. Tokura, K. Morobayashi, Y. Noro, and Y. Ishii: J. Jpn. Soc. Precis. Eng., 2001, vol. 67, pp. 322-26.
104. M. Behi: US 2006/0054856, 2006.

105. MPR: Metal Powder Rep., 2006, vol. 61(10), pp. 22-27.

106. S.W. Kennedy: Met. Powder Rep., 1990, vol. 45 (9), pp. 597-99.

107. G. Schlieper: PIM Inter., 2009, vol. 3 (1), pp. 21-27.

108. M. Qian: Int. J. Powder Metall., 2010, vol. 46 (5), pp. 29-44.

109. K. Ameyama, Y. Kaneko, H. Iwasaki, and M. Tokizane: Zairyo/ J. Soc. Mater. Sci., 1990, vol. 39, pp. 120-25 (in Japanese).

110. T. Ieki, T. Katoh, A. Matsumoto, T. Masui, and K. Andoh: J. Jpn. Soc. Powder Metall., 1997, vol. 44, pp. 448-52.

111. E. Nyberg, M. Miller, K. Simmons, and K.S. Weil: Mater. Sci. Eng., C, 2005, vol. 25 (3), pp. 336-42.

112. S. Guo, H. Zhang, R. Zhang, X. He, M. Qin, and X. Qu: Beijing Keji Daxue Xuebao/J. Univ. Sci. Technol. Beijing, 2007, vol. 29, pp. 721-24.

113. H. Miura, T. Takemasu, Y. Kuwano, Y. Itoh, and K. Sato: J. Jpn. Soc. Powder Metall., 2006, vol. 53, pp. 815-20.

114. O.M. Ferri, T. Ebel, and R. Bormann: Mater. Sci. Eng., A, 2009, vol. 504 (1-2), pp. 107-13.

115. G.C. Obasi, O.M. Ferri, T. Ebel, and R. Bormann: Mater. Sci. Eng., A, 2010, vol. 527, pp. 3929-35.

116. O.M. Ferri, T. Ebel, and R. Bormann: Proceedings of the $139^{\text {th }}$ TMS Annual Meeting \& Exhibition, TMS, Seattle, WA, 14-18 February, 2010, vol. 3, pp. 170-76.

117. Y. Itoh, T. Uematsu, K. Sato, H. Miura, and M. Niinomi: J. Jpn. Soc. Powder Metall., 2006, vol. 53 (9), pp. 750-54.

118. S. Terauchi, T. Teraoka, T. Shinkuma, and T. Sugimoto: J. Jpn. Soc. Powder Metall., 2000, vol. 47 (12), pp. 1283-87.

119. Y.C. Kim, S. Lee, S. Ahn, and N.J. Kim: J. Mater. Sci., 2007, vol. 42, pp. 2048-53.

120. H. Zhang, X. He, X. Qu, and L. Zhao: Mater. Sci. Eng., A, 2009, vol. 526 (1-2), pp. 31-37.

121. R. Gerling, E. Aust, W. Limberg, M. Pfuff, and F.P. Schimansky: Mater. Sci. Eng., A, 2006, vol. 423 (1-2), pp. 262-68.

122. Y. Itoh, H. Miura, K. Sato, and M. Niinomi: Mater. Sci. Forum, 2007, vol. 534-536, pp. 357-60.

123. T. Osada, H. Miura, Y. Itoh, M. Fujita, and N. Arimoto: J. Jpn. Soc. Powder Metall., 2008, vol. 55 (10), pp. 726-31.

124. Y. Itoh, T. Uematsu, K. Sato, H. Miura, and M. Niinomi: J. Jpn. Soc. Powder Metall., 2008, vol. 55, pp. 720-25.

125. Y. Xu, H. Nomura, M. Takita, and H. Toda: J. Jpn. Soc. Powder Metall, 2001, vol. 48 (4), pp. 316-21.

126. H. Kyogoku and S. Kumatsu: J. Jpn. Soc. Powder Metall., 1999, vol. 46, pp. 1103-07.

127. M. Bram, A. Ahmad-Khanlou, A. Heckmann, B. Fuchs, H.P. Buchkremer, and D. Stöver: Mater. Sci. Eng., A, 2002, vol. 337 (1-2), pp. 254-63.

128. M. Köhl, T. Habijan, M. Bram, H.P. Buchkremer, D. Stöver, and M. Köller: Adv. Eng. Mater., 2009, vol. 11 (12), pp. 959-68.

129. L. Krone, J. Mentz, M. Bram, H.P. Buchkremer, D. Stöver, M. Wagner, G. Eggeler, D. Christ, D. Christ, D. Christ, S. Reese, D. Bogdanski, M. Köller, S.A. Esenwein, G. Muhr, O. Prymak, and M. Epple: Adv. Eng. Mater., 2005, vol. 7 (7), pp. 613-19.

130. L. Krone, E. Schüller, M. Bram, O. Hamed, H.P. Buchkremer, and D. Stöver: Mater. Sci. Eng., A, 2004, vol. 378 (1-2), pp. 185-90.

131. J. Mentz, M. Bram, H.P. Buchkremer, and D. Stöver: Adv. Eng. Mater., 2006, vol. 8 (4), pp. 247-52.

132. E. Schöller, L. Krone, M. Bram, H.P. Buchkremer, and D. Ståaver: J. Mater. Sci., 2005, vol. 40 (16), pp. 4231-38.

133. H. Kyogoku, S. Komatsu, K. Shinohara, H. Jinushi, and T. Toda: J. Jpn. Soc. Powder Metall., 1994, vol. 41, pp. 1075-79.

134. H. Kyogoku, S. Komatsu, I. Tsuchitori, and T. Toda: J. Jpn. Soc. Powder Metall, 1995, vol. 42 (9), pp. 1052-56.

135. Y. Itoh, T. Uematsu, K. Sato, H. Miura, M. Niinomi, and M. Ikeda: J. Jpn. Soc. Powder Metall., 2006, vol. 53, pp. 821-26.

136. N.E. Kamber, Y. Tsujii, K. Keets, R.M. Waymouth, R.C. Pratt, G.W. Nyce, and J.L. Hedrick: J. Chem. Educ., 2010, vol. 87 (5), pp. 519-21.

137. H. Hamilton: Method, WO/2011/045601 A1, 2011.

138. J. Capus: Met. Powder Rep., 2011, vol. 66 (3), pp. 9-12. 